\title{
Ethnic favouritism in Kenyan education reconsidered: When a picture is worth more than a thousand regressions
}

\author{
Rebecca Simson \\ Wadham College, University of Oxford, Parks Road, \\ Oxford OX1 3PN, UK \\ Email: rebecca.simson@wadham.ox.ac.uk
}

and

\section{Elliott Green}

London School of Economics and Political Science, Houghton Street, London WC2A $2 A E, U K$

Email:e.d.green@lse.ac.uk

Published in Journal of Modern African Studies 58, 3 (September, 2020): 425460

\begin{abstract}
Does a leader's ethnicity affect the regional distribution of basic services such as education in Africa? Several influential studies have argued in the affirmative, by using educational attainment levels to show that children who share the ethnicity of the president during their school-aged years have higher educational attainment than their peers. In this paper we revisit this empirical evidence and show that it rests on problematic assumptions. Some models commonly used to test for favouritism do not take adequate account of educational convergence and once this is properly taken into account the results are found to be unstable. Using Kenya as a test case, we argue that there is no conclusive evidence of ethnic favouritism in primary or secondary education, but rather a process of educational convergence among the country's larger ethnic groups. This evidence matters, as it shapes how we understand the ethnic calculus of politicians.
\end{abstract}




\section{INTRODUCTION}

Since the late colonial era primary school attainment has been growing rapidly across much of Africa. Enrolment has increased sharply across both rural and urban populations, while gender gaps have declined and are today negligible in many countries. Progress in secondary schooling has been more varied, but also shows steady enrolment growth in aggregate.

There remains debate, however, over the drivers of this diffusion of basic education and the role of ethnic politics in shaping its pace. Specifically, have these educational advances benefitted some ethnic or regional groups disproportionately? Several influential papers contend that ethnic politics matters to educational outcomes in Africa, as leaders favour their own districts and ethnic communities by targeting educational resources to them. This is expected to result in an uneven pace of attainment growth that bestows considerable advantage on children who share the ethnicity of the sitting president and/or minister of education (André et al. 2018; Alwy and Schech 2004; Franck and Rainer 2012; Kramon and Posner 2016; Li 2018).

This evidence has informed broader academic debates about the nature of resource distribution in multi-ethnic countries. Evidence from the education sector has been used to demonstrate that ethnic patronage permeates African societies. It provides a clear economic motivation for voting along ethnic lines as citizens can expect greater access to public resources if the candidate from their ethnic group wins (Carlson, 2015). The education sector is seen as particularly ripe for favouritist policies as education spending constitutes a large share of total government expenditure and is a club good, inasmuch as it can be targeted towards specific schools and regions, unlike pure public goods like clean air and national defence.

However, this understanding of ethnic patronage in Africa as resting on broad-based delivery of goods and services to politicians' ethnic groups, remains contested. Some scholars have argued that ethnic patronage in Africa is an elite game with little trickle-down to the 
population at large, as politicians can take the support of their own communities for granted (van de Walle, 2007). According to this perspective, there is no reason to assume that leaders would target broad-based services, such as primary education, towards their own ethnic communities. Another strand of the literature on ethnicity has argued that leaders of multiethnic states usually seek to avoid accusations of capture and threats to their rule by allocating resources in equal shares across all groups or regions (Azam, 2008; Francois et al., 2015). An alternative set of empirical studies has found some evidence in support of this theory. Francois et al. (2015) have shown that African leaders seek to balance cabinet appointments amongst all larger ethnic groups, while Simson (2019) finds that public sector employees in Kenya and Uganda are more regionally representative than educational disparities alone would predict. Similarly, a historical study of the Kenyan police force in the early decades of independence found no evidence that ethnicity was linked to preferential treatment, although it did influence and embolden the behaviour of policemen (Vanden Eynde et al., 2018). Finally, Kasara (2007) finds evidence that African presidents tend to tax the main cash crop products of their co-ethnics at a higher rate than other crops, suggesting a negative rather than a positive effect of being a co-ethnic of the president. This mixed evidence about ethnic discrimination in African settings thus offer conflicting perspectives on why and how ethnicity is politicised, and the distributional consequences this will have.

In this paper therefore, we return to and scrutinize the evidence of ethnic favouritism in primary and secondary education. We argue that it rests on shaky assumptions and remains far from conclusive. Because of the strong growth and convergence in attainment rates, counterfactual educational attainment growth is difficult to specify and invariably rests on debatable assumptions about how educational attainment would develop in a world absent of ethnic favouritism. The existing papers fail to lay out these counterfactuals and a more careful review of their models raises serious doubt about some assumptions. In Kenya moreover, our focus country, rapid educational attainment across all larger ethnic groups, and 
convergence between leaders and laggards, strongly overshadows any marginal advantage of sharing ethnicity with the president. Once we take this into account, we find no conclusive evidence of ethnic favouritism in education. This suggests that the evidence of broad-based ethnic benefits accruing from ethnic voting may be over-stated.

This paper uses the Kenyan case as its main example. We focus our attention on Kenya as a type of most-likely crucial case study (Gerring 2007), such that Kenya is the place where we would most likely expect to find evidence of ethnic favouritism in education, given the extant literature on this topic (Kramon and Posner, 2016; Li, 2018). Indeed, there is currently more scholarship on ethnic and regional favouritism in Kenya than in any other individual subSaharan African country (Burgess et al. 2015; Kramon and Posner 2016; Li 2018; Vanden Eynde et al. 2018; Simson 2019), which is arguably due to the highly ethnicized nature of Kenyan politics as well as to its high-quality data and the fact that it has experienced two ethnic presidential transitions. The fact that we do not find evidence of ethnic favouritism in educational outcomes in Kenya suggests that the much broader literature on ethnic and regional favouritism deserves closer scrutiny.

The rest of the paper is organised as follows. It starts by laying out some descriptive statistics on educational inequalities in Kenya, before discussing how ethnic favouritism is most appropriately conceptualized and measured. It then critiques the evidence of ethnic favouritism given by Franck and Rainer (2012), Kramon and Posner (2016) and Li (2018), showing both the conceptual problems with their models and weaknesses in their empirical results. Lastly, it reviews the evidence on the supply factors that are thought to drive ethnic favouritism and challenges the conclusions reached by Kramon and Posner (2016). It concludes with a reconsideration of the evidence on ethnic favouritism in education. 
In many African countries both primary and secondary attainment have grown rapidly since independence. Gender gaps have also fallen. Across the continent as a whole, the gross primary enrolment rate rose from 55\% in 1971 to $98 \%$ in 2014, while the primary completion rate $^{1}$ jumped from $46 \%$ to $69 \%$ over the same period, and the gender parity - the ratio of girls to boys - rose from 0.7 to 0.9 . Performance varies considerably across countries, but in the last decade, eleven countries attained primary completion rates above $80 \%$. Secondary school enrolment remains considerably lower, but rose from $17 \%$ to $43 \%$ (gross) over the same period and gender differences fell among secondary students too (WDI 2018).

Those countries approaching universal primary attainment will, by definition, have seen convergence in primary attainment levels. If all children today complete primary school, growth in attainment must have been faster among those groups or regions that started the period with levels below average. This, as we shall see, confounds any measure of ethnic favouritism, as illustrated using the Kenyan case below.

\section{The Kenyan case}

Kenya is often used to test theories about ethnic effects because it offers two clear and sharp transitions in leader ethnicity without the confounding effects of wars or coups, from a Kikuyu president (Jomo Kenyatta) to a Kalenjin president (Daniel Arap Moi) in 1978, and back to a Kikuyu president (Mwai Kibaki) in 2002. Researchers have exploited these leadership transitions to examine whether they coincide with a shift in the flow of public resources from Kikuyu to Kalenjin beneficiaries and vice versa, particularly in the case of primary and secondary schooling (Alwy and Schech, 2004; Franck and Rainer, 2012; Kramon and Posner, 2016; Li, 2018). Most of these studies use survey data to examine the educational attainment of a representative sample of Kenyans by birth year. The studies rest on the assumption that schooling is undertaken at set ages, and a person's year of birth

\footnotetext{
${ }^{1}$ I.e. gross intake ratio: number of entrants into the final year of primary schooling divided by size of age cohort.
} 
therefore indicates when said person attended school. Cross-sectional data on ethnic group educational performance over successive birth cohorts therefore offers a historical record of enrolment levels by year and allows researchers to test whether the relative educational performance of a given ethnic group changes amongst those cohorts that received their education in the years after a presidential transition.

Building on this approach, the three charts in Figure 1 compare average years of primary schooling for the Kikuyu, Kalenjin and the remaining population ('other') by birth year, for cohorts that would have attended school under the presidencies of Jomo Kenyatta and Daniel Arap Moi, respectively. These charts use pooled Kenyan census data, where ethnicity is proxied based on place of birth rather than self-reported ethnic identity. ${ }^{2}$ According to the ethnic favouritism literature, we should expect to see disproportionate access to schooling for Kikuyu children educated under President Kenyatta, and for Kalenjin children educated under President Moi.

\section{[Insert Figure 1 here]}

The first chart gives the years of primary schooling for each of the three groups by birth cohort. The second measures the relative attainment of Kikuyu and Kalenjin respondents, by dividing the group average years of schooling by the national mean. ${ }^{3}$ The last chart provides a measure of absolute differences, by subtracting the national mean level of education from the group average. In other words, how many more/less years of primary schooling do the Kikuyu/Kalenjin have than the average Kenyan? The vertical lines mark (roughly) the

\footnotetext{
${ }^{2}$ Kramon and Posner (2016) and Li (2018) in contrast use Demographic and Health Survey (DHS) data, which specifies ethnicity precisely, and use the census as an out-of-sample validation. Our decision to use the census data more extensively is discussed in Appendix 1; Appendix Figure 1 compares the two samples and shows that the trends are very similar. The census has the advantage that the sample is considerably larger and avoids the gender imbalance inherent in the DHS samples. Note also that we cap the cohorts under consideration, to respondents aged 20 and above, to avoid including students who have still to complete their education, as discussed in Appendix 3.

${ }^{3}$ Because we cannot assign ethnicity to respondents born in Nairobi, which have unusually high educational attainment rates, Nairobi-born respondents have been removed from the total and 'other' category. This omission has very little impact as the population share born in Nairobi is small $(<2 \%)$.
} 
cohorts that received most of their education under a Kikuyu and Kalenjin president respectively, assuming that primary schooling takes place when a child is 6-13 years of age.

The first chart shows that attainment grew steadily for all groups over the period under review, but, unsurprisingly, the growth in years of schooling slowed as groups began to approach the primary education ceiling of 8 years. The Kikuyu ethnic group started the postcolonial period with a pronounced educational advantage while the Kalenjin had a small disadvantage, but the gap between the two groups has shrunk over time.

This convergence process is more evident in the second and third charts. Relative to the national mean, the Kikuyu advantage (in percentage terms), fell sharply over Kenyatta's presidency and then stayed relatively constant during Moi's presidency (at roughly $15 \%$ above the national mean), while the Kalenjin rose relative to the national mean under Kenyatta's presidency, and then steadied. The same trend is evident on an absolute basis. The gap in number of years of schooling to the national mean closed over the Kenyatta years, then stayed relatively steady at roughly $0.7-0.8$ years under President Moi.

The trends in secondary school attainment mirror the primary school trends, but with a lag (see Appendix Figure 2). The relative Kikuyu attainment declined under Kenyatta's presidency although the absolute gap in years continued to increase, while the Kalenjin relative performance and gap with the mean began to close roughly midway through Kenyatta's presidency and continued into the beginning of Moi's presidency. The Kikuyu gap increased again from about 1990, during Moi’s presidency.

Given these many different dynamics affecting primary attainment - an unequal postcolonial starting point, strong attainment growth across all larger Kenyan ethnic groups, convergence in years of schooling between those with a head-start and the laggards, as well as the complication that years of schooling has an upper bound after which no further progress can be measured - how exactly should we define and measure ethnic favouritism in educational 
access? The Kikuyu educational advantage was on average larger under Kenyatta than under Moi and vice versa for the Kalenjin, but essentially all the Kikuyu-Kalenjin convergence happened under Kenyatta's presidency. Furthermore, neither group saw attainment levels decline under a non-co-ethnic president. In absolute terms, Kikuyu children continued to outperform the Kalenjin throughout Moi's presidency too.

If Kenyatta and Moi's presidential terms had been swapped, and a Kalenjin president governed Kenya between 1964 and 1978, are we right to expect a different trend? Would the Kikuyu educational advantage have been erased overnight through quotas or immediate removal of educational resources from Kikuyu districts? Would the Kalenjin disadvantage have disappeared immediately? Furthermore, how much of the relative educational performance of ethnic groups should be attributed to government policy in the first place, and how much was driven by decisions by families and communities themselves? Lastly, are inequalities in access to education the most appropriate means of measuring favouritism in education provision, or might differences in educational quality across groups have provided another means by which politicians could favour their own? The next section reviews evidence about the drivers of educational attainment and discusses ways of conceptualizing and measuring inequality, fairness and favouritism.

\section{WHAT DRIVES EDUCATIONAL ATTAINMENT GROWTH?}

The literature on educational attainment usually distinguishes between demand and supply factors that influence household decisions to send their children to school (Handa, 2002; Dostie and Jayaraman, 2006). Schooling is rarely costless. In developing countries in particular, a large share of the costs of basic schooling are often borne by households or local communities, in the form of school fees, levies, uniform requirements, community contributions to school management or construction, as well as the opportunity cost of keeping children in school rather than in productive labour. Demand for schooling is 
therefore thought to be shaped by the expected returns to education and the household's ability to pay, as evidenced by a large body of recent empirical research (Dostie and Jayaraman, 2006; Deininger, 2003; Lincove, 2009). Most of these studies find household income or wealth have a positive effect on schooling outcomes. Many also find that attitudes towards education, proxied by parental education, are important independently of income. Furthermore, the expected returns to education - namely the future income of the educated graduate - will shape the family's cost-benefit analysis and increase investment in education (Goldin and Katz 1999). Thus economic change in a given region, that increases or decreases demand for skilled workers, could create differential demand conditions for education across a country.

Government policies may amplify or mute these demand forces. By bearing the costs of primary or secondary schooling, government policies will decrease the opportunity cost of sending children to school. Active regional policy or affirmative action, which channel more funds to underperforming areas, may help to level the playing field by making education more attractive - all else considered - in the poorest areas. In contrast, policies that rely on household or community co-financing to unlock government funds (also common in many countries), could amplify inequalities as richer communities are more able to raise the locally required contributions (cf. Mwiria, 1990, for an example from Kenya). When schooling is locally financed (whether through local taxes or community contributions), average educational attainment in the community as well as the strength of community cohesion are thought to influence the level of educational investment (Goldin and Katz, 1999).

\section{The Kenyan case}

How has the Kenyan government organised the supply of education? During the colonial era, 'ethnic favouritism' in Kenya was institutionalised, in the sense that the educational system was officially segmented by race and a disproportionate share of budget resources were 
devoted to educating the small white settler minority, and to a lesser extent, the Asian minority (Eshiwani 1990). Racial segregation in education was abolished in 1960. Within the African population, ethnic differences in attainment were also large, and strongly shaped by the degree of missionary penetration and integration into the colonial cash crop economy in the first half of the $20^{\text {th }}$ century (Olson 1972; Tignor 1976; Frankema 2012). Communities closer to the main urban metropolises (Nairobi, Mombasa, Kisumu) tended to be better educated.

In the early independence era, Kenya's education policies sought first and foremost to reverse the racial inequities of the colonial era. Concerns about inadequate supplies of high-level manpower (secondary schooled graduates and beyond) were deemed by many African governments to be the bigger obstacle to development than an underdeveloped primary school system. Resources were therefore disproportionately directed to the secondary and tertiary level with the expectation that local resources would finance primary schooling (Oketch and Rolleston, 2007; Olson, 1972). In the first decade of independence, funds for primary school construction and teachers' houses were raised locally, while the central government provided some or all recurrent outlays (teacher salaries and supplies) once the physical facilities had been built (Eshiwani, 1990, p.25). Kenya's secondary schooling system, meanwhile, had two tracks, with a largely state-funded national or provincial secondary school system of higher quality and higher unit cost, and locally funded, low quality (and less competitive) harambee schools (Mwiria, 1990).

With time however, policies came to stress the importance of education for national integration, rather than skills development alone. From a decentralized education system, where much of the provision was in the hands of missions and local governments, the central government gradually assumed greater control over educational resources. The 1968 Education Act brought education policy and financing under the purview of the Ministry of Education with a view to improving distributional outcomes. The 1976 National Committee 
on Educational Objectives and Policies made reduction of regional disparities in educational attainment a prime government objective. The first development plan under President's Moi's rule sought to increase educational opportunities in remote areas and among underprivileged groups (Kenya Development Plan 1979-1983, Part 1, p.21 and p.152).

With this policy justification, in the 1970s central governments began to assume a greater share of both primary school financing while secondary school financing was spread more evenly across schools (Oketch, 2004; Mwiria, 1990). Primary school fees were abolished (although shortly thereafter they were partially reintroduced), while the independent harambee secondary schools were gradually incorporated into the assisted school sector. Under President Moi’s leadership, secondary schooling policies were designed to level opportunities by focusing new school construction in underserved provinces. In 1984 the school system was reformed, lengthening the primary school cycle from seven to eight years, and reducing secondary schooling from six to four years, with a view to making secondary schooling less elitist.

With donor encouragement, primary education received greater budgetary attention in the 1990s. In the 2000s, under President Kibaki, the government committed to free primary schooling and shifted more resources to the primary system, including through a major programme to support primary school construction targeting arid and semi-arid regions where school density is low, and in urban slums with high levels of overcrowding (Ministry of Education Science and Technology, 2005). Alongside the democratisation of the public schooling system came the growth of private primary education supply, which today accounts for roughly a quarter of all primary schools and $16 \%$ of primary enrolment (Ministry of Education Science and Technology, 2014).

Some of these shifts are reflected in the structure of education spending. Table 1 gives the share of education spending by level of education, and rough relative estimates of per student 
spending. Primary education spending increased relative to total education spending in the 1970s with the expansion in enrolment and abolition of fees, while secondary schooling costs declined proportionately. In the 1980s primary education spending declined again, as the expansion of secondary and tertiary enrolment increased. The 1990s saw a shift back towards spending on primary schooling (as strongly encouraged by the international donor community). Tertiary education spending increased until the 1990s (to accommodate growing student numbers), then declined as the costs of tertiary education were increasingly transferred to students. Interestingly, these shifts do not accord neatly with Presidential shifts. Even though ethnic inequality increases at higher levels of the educational ladder, President Moi did not dismantle Kenya's regressive education structure that channelled a considerable share of spending to a slim and particularly ethnically skewed group of tertiary students.

\section{[Insert Table 1 here]}

In view of these education priorities and policies, and given Kenya's ethnic heterogeneity, how would we expect ethnic inequalities in access to have evolved over this time period, irrespective of any ethnic favouritism?

In the colonial and early independence period, when communities and households stood for a greater share of school costs, demand factors seem likely to have exacerbated inequality at primary school level. Communities with an educational head-start are likely to invest more in the schooling of their children, both because they can afford larger educational outlays, and because a greater number of highly educated people ensures that there are more people in the community who place a high social value on education. Demand is also thought to be higher in urban areas, both because urban earnings tend to be higher, and because the high returns to education are more visible. Ethnically cohesive communities may also have possessed an advantage over multi-ethnic ones, if they proved better at mobilizing local resources or 
petitioning for government support (Miguel, 2004). Working against these demand forces - at least in latter periods - was a supply of educational inputs that, officially at least, targeted disadvantaged regions.

Differences at secondary level will likely amplify inequalities at primary level. In Kenya in the 1960s and 1970s the government sought to equalize the proportion of primary school graduates that transitioned to secondary school at the provincial level (Gould, 1974, p.385). Province-level attainment was therefore a direct function of primary completion rates. Under Moi's presidency in the 1980 s, provincial secondary schools began reserving $85 \%$ of school places for students local to the province (Mwaniki, 2014, p.5). In regions where educational performance was weaker, this was expected to protect local candidates from competition from higher performers in other parts of the country. Meanwhile, national secondary schoolsthe most competitive of Kenya's secondary schools, albeit catering to only a small share of students - operated province-level quota systems, designed to equalise access (Gould, 1974; Mwaniki, 2014).

\section{PREDICTING ATTAINMENT GROWTH IN MULTI-ETHNIC SETTINGS}

Given these countervailing demand and supply forces, we would expect colonial era inequalities in education to persist for some time. In this context, what would trends in educational access look like if they were entirely unencumbered by ethnic favouritism, and how should we measure favouritism in relationship to this counterfactual?

Absolute inequality. In one sense, level differences alone are a measure of privilege or favouritism irrespective of attainment growth, at least if most of the costs of primary schooling are financed by the central government. If average primary attainment among Kikuyus stayed constant at six years of schooling, while that of the Kalenjin grew from two to six, the government would nonetheless have spent more resources on the education of 
Kikuyu children over the full duration of the period (assuming equal per student spending). Kikuyu communities would thus have received a disproportionate share of total state resources. This assumes however, that educational attainment is solely a function of government spending, which is patently not the case in most African countries. It also assumes that governments have the autonomy and power to radically redirect resources from one region or community to another. Such radical redistribution may be politically unfeasible, irrespective of the president's ethnicity, given the literature from economics on loss aversion (Tversky and Kahnemann, 1991). In the context of Kenya moreover, this definition of fairness would imply that Kikuyu communities were favoured under both the Presidencies of Kenyatta and Moi, given that their attainment levels, and thus presumably state per capita spend on education, were higher for the Kikuyus than for any other group under both presidencies.

Absolute change. If we assume that all communities clamour for continued attainment growth, and depend largely on government support to meet this demand, we might instead compare absolute gains in attainment. Rather than seeking to equalize attainment levels, we assume that the government will try and equalize the amount of additional, new resources it delivers to each group. In other words, we would consider the situation fair if, over a given period, the Kalenjin attainment rate grew from two to three years, while the Kikuyu rate grew from six to seven. In this scenario the absolute attainment gap between groups remains constant. This measure, however, loses relevance when as one group begins to approach the upper limit. If the Kalenjin attainment grows from two to three years while the Kikuyu rate, already nearing the maximum number of primary years of schooling, stays constant, the Kalenjin group would be considered the favoured group.

Percentage change. Alternatively, if we place more weight on demand as the driver of attainment growth and assume a laissez-faire system, we might expect the absolute gains to be largest in the communities that already have a head-start. Where few people are 
benefitting from schooling already, additional demand for schooling and social pressure to send children to school may be low (cf. Olson 1972, for an example from Kenya). ${ }^{4}$ Groups with higher attainment levels, conversely, may have larger numbers of expectant children clamouring to go to school. Moreover, it may well be that such groups are located in regions where returns to education are higher (more urbanized regions for instance), amplifying these demand forces. We may therefore speculate that in the absence of government intervention the growth rate in the years of schooling would be equal across groups. In other words, we would expect that in a system unencumbered by ethnic favouritism, both groups might see attainment growth of for instance $10 \%$ in a given year, from 2 years to 2.2 years for the Kalenjin for instance, and 6 years to 6.6 years for the Kikuyu. However, measuring percentage change suffers from the same upper bound problem as when measuring absolute change. Once a group approaches the upper limit, the rate of growth must slow. It also has the perverse implication that absolute gains will continue to be largest among the high achieving groups.

An alternative approach is to assume a quadratic growth function, where for each ethnic group, the rate of attainment growth slows as values approach the upper limit. As each ethnic group has a different starting point, we would predict different rates of attainment growth across groups, depending on where the group lies on the curve. However, this makes the notion of favouritism far less intuitive, as favouritism is defined in relationship to a complex counterfactual, where levels and rates of attainment growth will vary across ethnic groups and time. It is conceivable that a group would be considered favoured even if its attainment levels are stagnant while other groups experience growth.

Achievement and improvement indices. Alternatively, if we assume that incremental gains in schooling are harder to make at a higher level of achievement, i.e., we assume convergence

\footnotetext{
${ }^{4}$ In predominantly pastoral communities for instance, the uptake of education has lagged agrarian regions, despite large governmental and non-governmental investments.
} 
as the default, then improvement indices offer an alternative measurement approach. These functions are designed for measures that have 'asymptotic limits', with minimum and maximum achievement levels, such as years of primary schooling on infant deaths per 1,000 (Kakwani 1993). Sen (1981) has proposed that we measure the achievement as the percentage decrease of the difference between initial level and upper limit. Thus a gain from two to three years of schooling is measured as a change of one year, over a gap of five years to the upper limit of seven years, for an achievement index of 0.2 , while a gain from six to seven (where seven is the maximum), gives an achievement of one.

This method has primarily been used to measure health variables such as life expectancy and infant mortality. It is less obvious that the relative achievement in approaching universal primary education is quite as stark as in the health example. To give an example, in a country with a seven-year primary school system, Sen's model would consider the raising of primary attainment from six to seven years a greater achievement than raising it from zero to six. The former group, in this example, would be the favoured group.

Other dimensions of ethnic favouritism. Most of the measures of ethnic favouritism focus on quantity of education provided; how many students across different groups have benefit from educational access. It is also possible that politicians favour their ethnic kin by increasing the quality of education supplied, by, for instance, improving the quality of educational facilities or disproportionately deploying trained teachers to a given region. Existing literature suggests that this quality channel is less politically attractive than the quantity channel, given the importance politicians tend to place on visible quantifiable achievements such as school construction (Keefer and Khemani 2005; Harding and Stasavage 2014). Nonetheless, it is worth recognizing that a focus on more easily measured dimensions of educational benefits such as years of schooling could mask other means by which groups or individuals are favoured. 
Perception indicators? Irrespective of statistical models or definitions of fairness, for these definitions of ethnic favouritism to hold analytical relevance, they also need to be anchored in popular perceptions and understandings of favouritism. The reason political scientists study ethnic favouritism is not because of normative notions of fairness, but because they assume that ethnic favouritism or discrimination influences political behaviour, by fuelling support for politicians or grievances that may result in poor policy outcomes, conflictual elections or outright conflict. Yet imagine a situation where the Kikuyu attainment rate has grown from 6 to 7 years and the Kalenjin from 2 to 3.5 years, which, using an improvement index or assuming a counterfactual quadratic growth path as the counterfactual, would lead us to the conclusion that the Kikuyu ethnic group was favoured. Would the average layman, even if presented with these statistics, perceive this to be favouritism, or are absolute level differences or absolute change, regardless of their causes, a greater source of contention? Furthermore, could smaller growth rate differentials be perceived by the public with any accuracy, in the absence of detailed analysis and high statistical literacy?

\section{REVISITING THE EVIDENCE OF ETHNIC FAVOURITISM IN EXISTING PAPERS}

How do the existing papers on ethnic favouritism model their counterfactual world absent of ethnic favouritism? Kramon and Posner (2016) offer three alternative models. Their first and model, also replicated by Li (2018), predicts the number of years of schooling of a respondent, conditional on being of school age during the tenure of a co-ethnic president and controlling for time fixed effects and ethnic group fixed effects. Based on this model their results suggest that being a co-ethnic of the president during one's school-aged years boosts one's number of years of primary schooling by $6 \%$, and secondary schooling by $12 \%$.

By including a simple ethnic group fixed effect, the authors are assuming that in the absence of ethnic favouritism, we would observe a constant absolute gap in years of schooling 
between groups and over time. Given that primary attainment levels in Kenya are approaching the upper limit, ${ }^{5}$ this is a problematic assumption. It risks confusing the decrease in the size of this ethnic dummy, owing to convergence effects, with ethnic favouritism. This is illustrated in Figure 1, which shows that the absolute gap in mean years of primary schooling between the Kikuyu and national average was higher during the Kenyatta period than the Moi period and vice versa for the Kalenjin, but that this gap was largely a consequence of higher Kikuyu attainment under colonial rule. All the narrowing in the attainment gap happened during Kenyatta's presidency, while the gap between the two groups stayed constant under Moi's presidency. While it would be accurate to describe the inequalities under Kenyatta as larger than under Moi, it is hard to see how this can be attributed to President Kenyatta's disproportionate spending in Kikuyu regions. Rather, Kenyatta's presidency was characterised by educational catch-up by non-Kikuyu ethnic groups.

In a second specification, designed to control for the possible effects of convergence, Kramon and Posner (2016) introduce a linear ethnic-group specific time trend in addition to year and ethnic group fixed effects. Introducing a linear time trend assumes that all ethnic groups will see steady growth in years of schooling, although these rates of growth are allowed to differ between groups. Ethnic favouritism is then measured by examining whether the annual rate of change in years of schooling for a given group is smaller or larger than its mean during a period when the president was of its ethnicity.

However, this tweak to the model does not overcome the convergence problem just discussed in relation to using ethnic group fixed effects. Clearly the attainment growth rate will slow as groups approach eight years of primary schooling (or four years of secondary schooling). Because the Kikuyu start butting against the years of primary school ceiling earlier than the

\footnotetext{
5 The upper limit was 7 years up until 1984, and then extended to 8 years.
} 
Kalenjin, their rate of attainment growth slows more quickly under Moi's presidency than it does for the Kalenjin, and this will therefore be identified as ethnic favouritism in the model.

The third specification offers a more defensible counterfactual. Rather than assuming that years of schooling will grow linearly, it assumes that each group follows its own quadratic time trend. In other words, the growth in years of schooling is predicted to take a parabolic form. In every ethnic group, attainment will grow faster at lower levels of attainment and slow down as the attainment level approaches 8 years of primary schooling. The model allows the pace of growth and pace of slow-down to vary by group. This specification is similar to the model used by Franck and Rainer (2013), who use DHS data to examine ethnic favouritism in relation to ethnic group- and survey-specific quadratic time trends. ${ }^{6}$ They, like Kramon and Posner, find an educational advantage for presidential co-ethnics in Kenya, relative to the predicted quadratic growth trend in primary schooling.

While this approach takes better cognizance of convergence forces, it creates a very abstract notion of ethnic favouritism, defined as a rate of educational attainment growth higher than what would be predicted by an ethnic-group specific quadratic time trend. This can give some unintuitive interpretations. Depending on the trend, we may capture an ethnic favouritism effect even where the favoured group sees no attainment growth at all. Over longer periods of time, moreover, it is not clear that quadratic time trends will approximate the growth path of years of primary education.

This conceptual concern aside, however, we find that the results reported using these models are highly unstable. To demonstrate this, we replicate Kramon and Posner's model using quadratic group-specific time trends and then subject it to a number of robustness tests, as seen in Table 2. The results of a first, 'narrow' replication, that seeks as far as possible to replicate the original model, validate the results reported by Kramon and Posner. The

\footnotetext{
${ }^{6}$ Franck and Rainer's (2012) main results consider whether a respondent has some, or has completed primary education, rather than measuring years of primary schooling.
} 
coefficient is positive and significant. ${ }^{7}$ This result suggests that students educated under a coethnic president receive a boost in average number of years of primary schooling of 0.18 years, which corresponds to a roughly $3 \%$ increase relative to average years of primary schooling, or 0.07 standard deviations.

However, Kramon and Posner's dataset, for unexplained reasons, constructs a birth year variable by subtracting a respondent's age from the survey year, despite the fact that the DHS contains a precise birth year variable. In Model 2 we replace the birth year, match, time and cohort variables with ones constructed based on a respondent's actual reported birth year instead of the estimated birth year. This small adjustment reduces the size of the match coefficient and it loses statistical significance. In Model 3 we expand the sample using data from the 2014 DHS, which has become available since the publication of Kramon and Posner's paper. This roughly doubles the sample size. Under this specification the match variable changes signs and remains insignificant. In Model 4 we drop all the control variables (as the motivation for their inclusion is dubious, as discussed in Appendix 4). This has no major impact on the results. In Model 5 we only include respondents aged 20 or above, to avoid biases resulting from ethnic group differences in average primary completion age. ${ }^{8}$ The match coefficient remains negative and insignificant.

Lastly we extent the time period under review to include birth cohorts born in 1950 or later, and thus some respondents educated in the last years of colonial rule. This alteration does give us a positive and significant match coefficient, albeit of smaller size. This suggests that the results are driven by the period of transition from colonial to independent rule. Inclusion or exclusion of the cohorts educated around independence seem to drive the size and

\footnotetext{
${ }^{7}$ Note that our sample is slightly smaller than Kramon and Posner's (47,146 versus 47,275 observations). We were unable to account for this very slight difference.

${ }^{8}$ In Appendix 3 we show that by having a relatively low age cut-off for inclusion in the sample introduces sampling biases. Many students have yet to complete their primary education until late into their teens and the ethnic origins of the overaged versus 'correctly' aged primary students differs.
} 
significance of the coefficient. ${ }^{9}$ Given the big expansion of educational provision around this time and changing policy priorities, it seems hasty to attribute an increase in the Kikuyu share of students in these transition years solely to ethnic favouritism by President Kenyatta.

[Insert Table 2 here]

Table 3 presents our next set of results that replicate Kramon and Posner's model using censuses, rather than DHS data, which increases the sample size to the millions. The first model replicates Kramon and Posner's model with quadratic group-specific time trends as closely as possible, but excludes religious and birth place controls as these cannot be constructed from the census dataset. This model shows a positive and statistically significant ethnic match dummy of comparable magnitude to that found by Kramon and Posner. In Model 2 we restrict the sample to respondents aged 20 or above. This reduces the coefficient size slightly and the results are now only significant at the $10 \%$ level. Yet moving the start date of the sample by just one year, to those born from 1955 as opposed to from 1954, brings the coefficient down in size and it loses significance. Conversely, including more colonial era cohorts, by extending the window back to 1950, increases the coefficient size. As in the previous analysis then, these results are driven by the period of transition to independence.

[Insert Table 3 here]

We can illustrate these results visually, by plotting the predicted years of primary schooling for the Kikuyu in a world absent of ethnic favouritism (i.e., setting the ethnic match dummy to zero). This predicted trend is then compared to the actual ethnic group trend in Figure 2.

\footnotetext{
9 The reason the coefficient loses significance in model 2 is that actual birth year excludes a number of respondents born in the latter half of 1953.
} 
We focus on the Kikuyu as it appears that the educational performance of this ethnic group in the early independence period is driving the results. The actual Kikuyu trend (black line), is shown alongside the predicted trends using the three alternative start years from Modules 2-4 above using census data: 1954, 1955 and 1950.

[Insert Figure 2 here]

This illustrates visually how sensitive the results are to educational performance among the cohorts born just around 1954. There appears to be something of a kink-point in the data, with a take-off in the educational growth for the Kikuyu cohorts born 1955 and later. Consequently, the predicted quadratic time trend is sensitive to the starting year. It tracks the actual trend more closely when we model from a peak start year (1955), and performs worse when we use the trough years 1954 or 1950 . Another confounding factor apparent in this figure is that the difference between the Kikuyu actual and predicted trends in the Kenyatta era is driven largely by trough years, which are a result of age heaping. ${ }^{10}$ Thus the deviation between actual and predicted trend may partly be a consequence of less age heaping among Kikuyu respondents.

Moreover, contrary to what we would expect if these trends were driven by ethnic favouritism, there is no obvious break in trend for cohorts born around 1969, which corresponds to the crucial transition from President Kenyatta to President Moi. To examine this further, we introduce two placebo tests (Table 3, Models 5 and Model 6). ${ }^{11}$ Following Kramon and Posner, these models 'incorrectly' code the transition from Kenyatta to Moi's

\footnotetext{
${ }^{10}$ The reason for this is that uneducated respondents are less likely to know their exact age. These less educated respondents will therefore cluster on rounded age numbers (5s and 10s), and pull down the average years of schooling among those cohorts, giving a zigzagging trend.

${ }^{11}$ These placebo tests are modelled on those used by Kramon and Posner (pp.19-20).
} 
presidency as having happened three years prior to the actual transition (Model 5), and three years after the actual transition (Model 6) (using Model 4 as the base specification). In both cases the match dummy coefficient remains significant, and in the first specification it increases in size and significance. Thus the placebo test fails to demonstrate an effect of the identified presidential transition year on primary school enrolment.

\section{Favouritism in secondary schooling}

Next we turn to examining ethnic group educational trends in secondary schooling. While Franck and Rainer (2013) focus only on primary school completion, Kramon and Posner (2016) examine secondary school attainment using the same set of specifications as for primary schooling to measure favouritism. They argue that their stronger results at secondary level supports their thesis, as ethnic patronage is more likely to manifest itself at secondary level where returns to schooling are higher and degree of state subsidization larger.

However, this approach to measuring ethnic favouritism overlooks the impact of primary schooling on secondary outcomes. Given that only students who have completed primary school are eligible for secondary schooling, there is a path dependency to secondary school inequalities, which makes it problematic to consider secondary attainment independently of primary attainment. It would therefore be more appropriate to measure favouritism in secondary education in relation to the number of eligible pupils in each ethnic group, rather than the entire population.

Although the censuses and DHS do not ask respondents whether they passed their primary school exams, we can use attendance in the final year of primary schooling as a proxy for primary completion, assuming that ethnic differences in pass rates do not vary markedly over time. Figure 3a therefore measures average years of secondary schooling by ethnic group conditional on having at least seven years of primary schooling, while Figure $3 \mathrm{~b}$ measures 
this transition rate in relationship to the national mean. ${ }^{12}$ In other words, we are examining what share of primary school completers from each ethnic group obtain secondary education. The differences in performance between the groups are much smaller once differences in primary schooling are controlled for. The Kikuyu retain a small advantage throughout the period, but the gap between the Kikuyu and Kalenjin transition rates declined primarily under Kenyatta's presidency, not Moi's. Kikuyu primary school completers continue to maintain an advantage over the Kalenjin and other groups throughout Moi's presidency, and this advantage increases among the cohorts educated under the last years of President Moi's presidency.

When comparing the transition rate across ethnic groups, the presence of a convergence effect is less obvious. Figure 3 a does not suggest that the transition rate has followed either a linear or quadratic time trend. To test for a possible ethnic favouritism effect, we therefore revert to Kramon and Posner's base specification, which controls only for group and time fixed effects (assuming no group-specific time trends). Results are given in Appendix Table 5 using the DHS and census data. The DHS dataset does yield give a positive and significant coefficient, but this coefficient loses significance when we limit the sample to the Kenyatta and Moi presidencies only, while the census specification gives a negative (and statistically insignificant) coefficient on the presidential ethnic match variable. This does not constitute clear evidence of ethnic favouritism.

Another piece of evidence allows us to bring schooling performance into the picture, and examine whether Kalenjin primary completers faced lower barriers to secondary school entry under President Moi, through either favouritism that lowered the grade point average required for Kalenjin candidates to enter secondary school, or a higher supply of secondary relative to

\footnotetext{
${ }^{12}$ A data problem is that the school reforms of 1984, which extended primary schooling in Kenya from 7 to 8 years. This may interfere with the results for the early 1970s, as we may not be able to pinpoint the exact respondents who completed their primary schooling under the old and new system. For simplicity, the figure therefore uses 7 years of primary schooling as the measure of 'completion' throughout the entire period.
} 
primary schools in predominantly Kalenjin districts. For a single year, 1989, we have districtlevel data on not only primary and secondary enrolment, but also the average student performance on the Kenya Certificate of Primary Education (KCPE). We can therefore examine the rate of transition from primary to secondary school at the district level, by measuring the share of secondary students to primary school exam candidates, while controlling for average district-level exam performance. This allows us to measure whether students from a particular ethnic region of Kenya face a lower or higher threshold to secondary school entry than others.

In Table 4 we present the results of regressing the average district KCPE score against the ratio of secondary school students to KCPE candidates by district, and include dummy variables for Kalenjin and Kikuyu districts. ${ }^{13}$ If Kalenjin districts were favoured under President Moi through the provision of more secondary school inputs or easier access to national secondary schools, we should expect to see a disproportionate share of Kalenjin students transitioning from primary to secondary schools and thus a positive coefficient on the Kalenjin dummy, while the Kikuyu dummy would be negative.

[Insert Table 4 here]

The results do not confirm these predictions. The Kalenjin transition rate is lower than that predicted by the model, although the coefficient is insignificant. There is no evidence that students in Kalenjin regions had a higher rate of educational progression than students in other regions. The Kikuyu dummy is likewise insignificant, albeit positive. It does not appear, therefore, that there was any absolute lowering of the bar for Kalenjin primary

\footnotetext{
${ }^{13}$ As the secondary school enrolment data is not disaggregated by form, we divide the total enrolment (Form 14) by 4 . As both the primary and secondary data is from 1989, we make the simplifying assumption that districtlevel enrolment did not vary substantially between 1985 and 1989.
} 
completers under Moi's Presidency, although in the absence of time series data we cannot measure whether the Kalenjin or Kikuyu transition rate changed following the presidential transition.

This data source also allows us to draw some tentative inferences about differences in educational quality across ethnic regions of Kenya. One alternative mechanism through which favouritism may operate is through differences in the quality of education supplied, rather than the quantity. The 1989 cross-sectional data allows us to look at differences in average candidate performance across ethnic regions, which can be thought of as a proxy for school quality. As seen in Appendix Table 6, the 1989 KCPE performance data shows considerable variation in average KCPE score across regions, although the variation in school-level KCPE averages within districts is more than twice as high as the variation between ethnic regions (measured by a coefficient of variation). Moreover, much of this variation is probably a consequence of differences in household income and educational status. With a few exceptions (Turkana, Mombasa), students tend to score higher in richer parts of Kenya where educational attainment is higher to begin with, and vice versa. In this regard, Kalenjin districts do not appear to be major outliers.

\section{FAVOURITISM IN THE SUPPLY OF SCHOOLS AND TEACHERS?}

One of the compelling aspects of Kramon and Posner's (2016) paper is that it offers a clean causal explanation for how ethnic patronage shapes educational inequalities. The authors argue that these ethnic inequalities in educational outcomes are supply driven, with, for instance, a Kikuyu-led government directing more state resources, such as the construction of schools, to Kikuyu districts. To test this, they examine the number of schools per district and conclude that school construction disproportionately benefitted districts in predominantly Kikuyu/Kalenjin districts under their respective coethnic presidents' tenure. 
However, a school to school-aged population ratio is only an appropriate measure of political favour under certain assumptions: firstly, that school construction was financed by the government, and secondly, that schools are roughly uniform in size. On closer inspection, neither of these assumptions hold.

In the first decades of independence, primary school construction in Kenya was primarily financed by the local community. It remained official policy until at least the 1980s that the development of physical facilities was the responsibility of school committees and parent associations, not the central government (Eshiwani, 1990, p.25). Some may have been financed through donations by politicians through harambee funds, which may indirectly have come from political spoils, but a community's number of wealthy harambee benefactors is likely to have been a function of far much more than the President's ethnicity. In latter decades aid has also been an important source of financing for school construction, which is presumably less susceptible to ethnic targeting. Furthermore, although hard to verify, the data used by Kramon and Posner does not appear to distinguish between public and private primary schools. By 2014, roughly a quarter of Kenyan primary schools were private. Private provision has been growing over time but varies considerably across counties. In Nairobi, $83 \%$ of primary schools were private in 2014, compared to 5\% in West Pokot (Ministry of Education Science and Technology, 2014).

Nor are Kenyan primary schools uniform in size. Unsurprisingly, denser and wealthier areas tend to have larger primary schools. The average number of students per school across Kenyan counties in 2014 ranged from 926 in Nairobi to 219 in Baringo and Tharaka-Nithi. It is therefore difficult to deduce, from data on the number of school alone, whether more schooling opportunities were being created in some districts relative to others.

An arguably less problematic measure of educational supply is the number of teachers in a given district. Unlike school construction, the Kenyan central government has been the main 
source of finance for teacher's salaries in public schools since independence. Data on number of teachers is available at province, if not always at district level. In Table 6 we therefore calculate the primary school-aged population to teacher ratio for each province in Kenya for a set of benchmark years, close a the year of presidential transition. Provinces roughly map onto at least some ethnic regions in Kenya, with the Kikuyu predominant in the Central province, and the Kalenjin comprising just under half the population of the Rift Valley. While cruder than a district measure, we would expect that ethnic favouritism in the supply of teachers would result in a disproportionate reduction in the population to teacher ratio in Central and Rift Valley provinces under the presidencies of Kenyatta and Moi respectively.

Note that at the primary level, the 1966 and 1977 data does not distinguish between public and primary schools, but accounts suggest that private primary schooling catered to a very small share of African students in the 1960s and 1970s. ${ }^{14}$ Data for 2003 and 2014 records the number of public school teachers only. Population data is taken from the censuses for cohorts aged 6-13. We interpolate between census years assuming a constant rate of population growth. The results are provided in Table 5.

[Insert Table 5 here]

Consistent with the attainment trends, the teacher to population ratios have converged over time. Over the course of Kenyatta's presidency (1966-77) the ratio of school-aged children to teachers dropped substantially across the country, but the Kikuyu-dominated Central province registered the smallest improvement. Over the course of Moi's presidency the population to teacher ratio stayed relatively constant, with small improvements in the Central, Eastern and Rift Valley provinces, while the teacher density fell dramatically in Nairobi

\footnotetext{
${ }^{14}$ Kinyanjui (1981) identified 14 private primary schools in Nairobi, Mombasa, Nakuru and Kisumu in 1976 (7\%), but these catered primarily to expatriates and Asian and European Kenyans, only 19\% of the students were African Kenyans in 1972.
} 
(presumably on account of rapid population growth and increased private primary schooling in the capital). Under Kibaki's presidency the population to teacher ratio increased even further in Nairobi, rose slightly in the Central, Eastern and Rift Valley, and remained relatively constant elsewhere. The coefficient of variation fell once more. Note that the main outlier region throughout the postcolonial era has been the North-Eastern province, where the teacher supply remains dramatically lower than in the rest of the country. Here too, however, the ratio has improved over time. ${ }^{15}$ Taken in sum, this does not provide strong evidence of favouritism. Kikuyu districts had unusually low rates of teacher growth under Kikuyu presidents. Kalenjin areas did experience comparatively strong growth in the teacher supply under Moi's presidency, but as with attainment, this is hard to distinguish from a broader catch-up effect.

\section{CONCLUSION}

This paper has reviewed some of the evidence of ethnic favouritism in African educational provision, much of which rests on the Kenyan example. Revisiting the Kenyan case shows the available evidence to be far from conclusive. When analysed descriptively, the trends in ethnic group educational attainment do not conform to any intuitive models of ethnic favouritism, and the regression results prove highly sensitive to the nature of the sample and years under review. The relative performance of the Kikuyu ethnic group declined under the Kikuyu presidency of Kenyatta, while the Kalenjin group saw their relative performance improve prior to the transition to a Kalenjin presidency. There is no evidence of clear ethnic group discontinuities around the time of presidential shifts.

In both the enrolment and input analysis, perhaps the more striking omission from the ethnic favouritism story is the noteworthy convergence in primary attainment across Kenya's larger ethnic groups (see Appendix Figure 7). Among Kenyan millenials - the last cohorts included

\footnotetext{
${ }^{15}$ Note also that the 2009 population of the North-Eastern Province suggests an unlikely rate of population growth, and may be over-estimated.
} 
in our sample born around 1989 - average years of primary schooling do not differ markedly across major ethnic groups, with a range from 6.3 (Kalenjin) to 7.4 (Kikuyu). In contrast, for the first cohorts to be educated in independent Kenya, the average years of schooling ranged from 3.3 to 5.4. The educational divide has, however, up until recently grown more marked between the larger ethnic groups in the Kenyan 'core', relative to smaller groups at the 'preiphery', particularly groups that retain pastoralism, notably the Somali, Turkana and Masai. While these gaps may be cause for concern, today's educational fault line does not map neatly onto the main political divides in Kenyan party politics.

In the Kenyan case the changing ethnic group attainment patterns are very hard to ascribe to government action in the first place, but are, if anything, more consistent with the idea that governments sought to balance access to popular, broadly-accessed services such as primary education roughly equally among regions. Yet one should also be careful not to read too much government agency into these patterns. Demand for education has been strong across most ethnic groups, and educational attainment growth, particularly at primary level, was largely driven by grassroots action rather than top-down planning. Furthermore, the rates of convergence in educational attainment are themselves conditional on the rate of attainment growth. During the periods when the educational system was expanding rapidly - which coincides with periods of strong economic growth - convergence also tends to be more rapid. The rapid educational convergence under Kenyatta, and slowdown under Moi, may have more to do with the changing economic conditions in Kenya than with any explicit educational policy shift.

A further consideration, not discussed in the reviewed papers, is the extent to which citizens of Kenya - or indeed any country - would be able to gauge these levels of supposed ethnic favouritism. It is usually assumed that ethnic favouritism serves a political purpose, by rewarding and cementing support for a leader from within his or her core constituency. But for this strategy to work citizens have to have a reasonably accurate perception of the 
privileged bestowed, or conversely withheld, from them. In a context of rising educational attainment across the entire country, it seems unlikely that the average Kenyan citizen would have any ability to judge the marginal advantage or penalty accrued by their ethnic group particularly if the measure of favouritism is conditioned on a hypothetical rate of educational convergence. Indeed, as Carlson (2018) argues based on experimental and Afrobarometer evidence, perceptions of favouritism may be greater in situations when individuals lack access to information about government expenditures and instead rely upon informal comparisons with members of other groups. Regardless of their historical causes, it may well be that absolute inequality between groups is more politically salient than relative rates of change under a particular presidency. 


\section{REFERENCES}

Alwy, Alwiya and Susanne Schech. 2004. "Ethnic Inequalities in Education in Kenya." International Education Journal 5.2 (2004): 266-74.

Andre, Pierre, Paul Maarek and Fatoumata Tap. Ethnic Favoritism: Winner Takes All or Power Sharing? Evidence from School Constructions in Benin. Mimeo, University of Cergy-Pontoise, France. (2018).

Azam, Jean-Paul. "The Political Geography of Redistribution." The Political Economy of Economic Growth in Africa, 1960-2000. Ed. Benno J. Ndulu et al. Cambridge: Cambridge University Press, 2008.

Carlson, Elizabeth. "Ethnic Voting and Accountability in Africa: A Choice Experiment in Uganda." World Politics 67.2 (2015): 353-385.

Carlson, Elizabeth. "The Relevance of Relative Distribution: Favoritism, Information and Vote Choice in Africa." Comparative Political Studies 51.12 (2018): 1531-1562.

Deininger, Klaus. "Does Cost of Schooling Affect Enrollment by the Poor? Universal Primary Education in Uganda." Economics of Education Review 22.3 (2003): 291-305.

Dostie, Benoit, and Rajshri Jayaraman. "Determinants of School Enrollment in Indian Villages." Economic Development and Cultural Change 54.2 (2006): 405-421.

Eshiwani, George S. Implementing Educational Policies in Kenya. World Bank Discussion Papers No. 85. Africa Technical Department Series. 1990.

Franck, Raphaël, and Ilia Rainer. "Does the Leader's Ethnicity Matter? Ethnic Favoritism, Education, and Health in Sub-Saharan Africa." American Political Science Review 106.02 (2012): 294-325.

Francois, Patrick, Ilia Rainer, and Francesco Trebbi. "How Is Power Shared in Africa?" Econometrica 83.2 (2015): 465-503.

Frankema, Ewout. "The Origins of Formal Education in Sub-Saharan Africa: Was British Rule More Benign?” European Review of Economic History 16 (2012): 335-355.

Gerring, John. Case Study Research: Principles and Practices. Cambridge: Cambridge University Press, 2007.

Goldin, Claudia, and Lawrence F. Katz. "Human Capital and Social Capital : The Rise of Secondary Schooling in America , 1910-1940." The Journal of Interdisciplinary History 29.4 (1999): 683-723.

Handa, Sudhanshu. "Raising Primary School Enrolment in Developing Countries: The Relative Imporance of Supply and Demand.” Journal of Development Economics 69.1 (2002).: 130-128.

Harding, Robin and David Stasavage. "What Democracy Does (and Doesn't Do) for Basic Services: School Fees, School Inputs and African Elections." Journal of Politics 76. 1 (2014): 229-245.

Kakwani, Nanak. "Performance in living standards: An international comparison." Journal of Development Economics 41.2 (1993): 307-336.

Kasara, Kimuli. "Tax Me If You Can: Ethnic Geography, Democracy, and the Taxation of Agriculture in Africa." American Political Science Review 101.1 (2007): 159-172. 
Keefer, Philip and Stuti Khemani. "Democracy, Public Expenditures and the Poor:

Understanding Political Incentives for Providing Public Services.” World Bank Research Observer 20. 1 (2005): 1-27.

Kenya. Ministry of Economic Planning and Development. Planning for progress: our fourth development plan, 1979-1983. Nairobi: Government Printers (1979)

Kinyanjui, Kabiru. "Education and inequality in Kenya: some research experience and issues." Institute for Development Studies, University of Nairobi, Working Paper 353 (1981).

Kramon, Eric, and Daniel N Posner. "Ethnic Favoritism in Primary Education in Kenya." Quarterly Journal of Political Science 11.1 (2016): 1-58.

Li, Jia. "Ethnic Favoritism in Primary Education in Kenya: Effects of Coethnicity with the President." Education Economics 26.2 (2018): 194-212.

Lincove, Jane Arnold. "Determinants of Schooling for Boys and Girls in Nigeria under a Policy of Free Primary Education.” Economics of Education Review 28.4 (2009): 474 484.

Miguel, Edward. "Tribe or Nation? Nation-Building and Public Goods in Kenya versus Tanzania." World Politics 56.3 (2004): 327-362.

Ministry of Education Science and Technology. 2014 Basic Education Statistical Booklet. N.p., 2014.

---. Kenya Education Sector Support Programme 2005-10. N.p., 2005.

Mwaniki, Munene. "Mother tongue education in primary teacher education in Kenya: a language management critique of the quota system." Multilingual Education 4.11 (2014): 1-17.

Mwiria, Kilemi. "Kenya's Harambee Secondary School Movement: The Contradictions of Public Policy." Comparative Education Review 34.3 (1990): 350-368.

Oketch, M., and C. Rolleston. "Policies on Free Primary and Secondary Education in East Africa: Retrospect and Prospect." Review of Research in Education 31.1 (2007): 131158.

Oketch, Moses O. "The Emergence of Private University Education in Kenya: Trends, Prospects, and Challenges." International Journal of Educational Development 24.2 (2004): 119-136.

Olson, Jerry B. "Secondary Schools and Elites in Kenya: A Comparative Study of Students in 1961 and 1968." Comparative Education Review 16.1 (1972): 44-53.

Sen, Amartya. "Public action and the quality of life in developing countries." Oxford Bulletin of Economics and Statistics 43.4 (1981): 287-319.

Tignor, Robert. Colonial Transformation of Kenya: The Kamba, Kikuyu, and Maasai from 1900-1939, Princeton: Princeton University Press (1976)

Tversky, Amos, and Daniel Kahneman. "Loss Aversion in Riskless Choice: A ReferenceDependent Model.” Quarterly Journal of Economics 106.4 (1991): 1039-61.

van de Walle, Nicholas. "Meet the New Boss, Same as the Old Boss? The Evolution of Political Clientelism in Africa." Patrons, Clients, and Policies: Patterns of Democratic Accountability and Political Competition. Ed. Herbert Kitschelt and Steven Wilkinson. 
Cambridge University Press, 2007. 50-67.

Vanden Eynde, Oliver, Patrick M Kuhn, and Alexander Moradi. "Trickle-Down Ethnic Politics: Drunk and Absent in the Kenya Police Force (1957-1970)." America Economic Journal: Economic Policy 10.3 (2018): 388-417.

\section{Data sources}

ICF. 1989-2014. Kenya Demographic and Health Surveys (various) [datasets]. Funded by USAID. Rockville, Maryland: ICF [Distributor], (2018).

Minnesota Population Center, Kenya Housing and Population Censuses 1969 - 2009, Integrated Public Use Microdata Series, International [datasets]. Minneapolis, MN: IPUMS (2018).

World Bank, World Development Indicators (2018).

$<$ http://databank.worldbank.org/data/reports.aspx?source=world-developmentindicators> 
Figure 1. Kenya: primary attainment by ethnic group

a. Average years of primary schooling by group b. Primary schooling by group relative to natl.
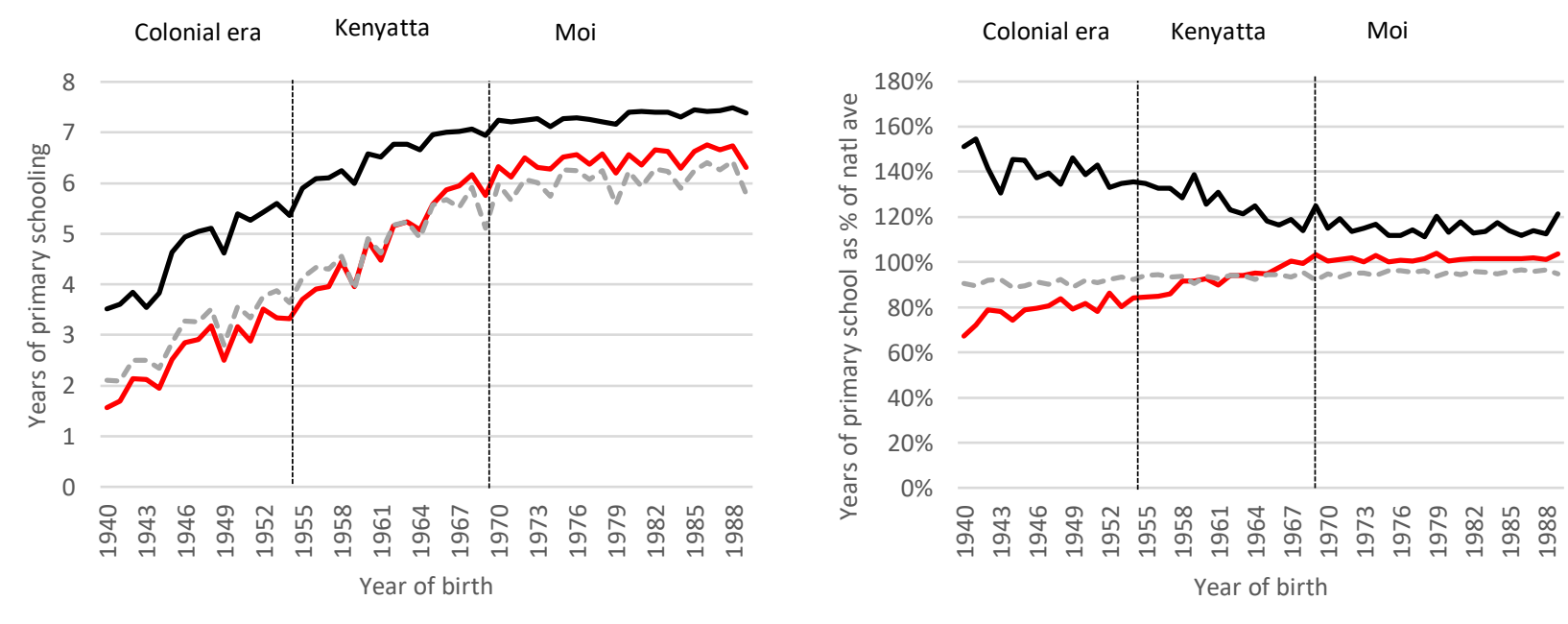

- Kikuyu Kalenjin $-\infty-\infty$ Other mean

c. Primary schooling by group, difference to

mean

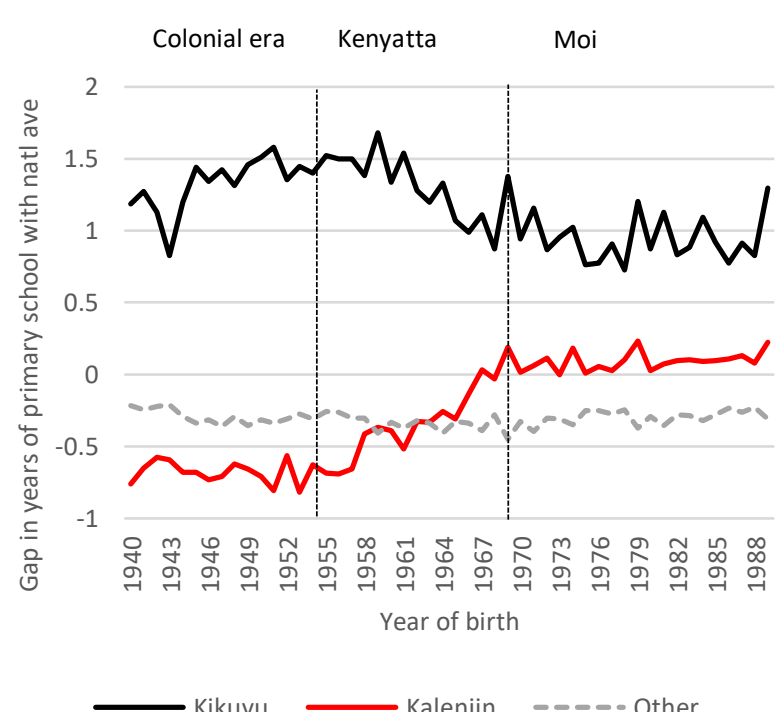

Note: Nairobi-born respondents excluded (constitute $<2 \%$ ); droplines mark cohorts who are expected to have received most of their schooling under the given 'regime'. Source: Pooled data from Kenyan 1969-2009 censuses, Minnesota Population Center, 2018. 
Figure 2. Kikuyu years of primary schooling by birth cohort, predicted versus actual

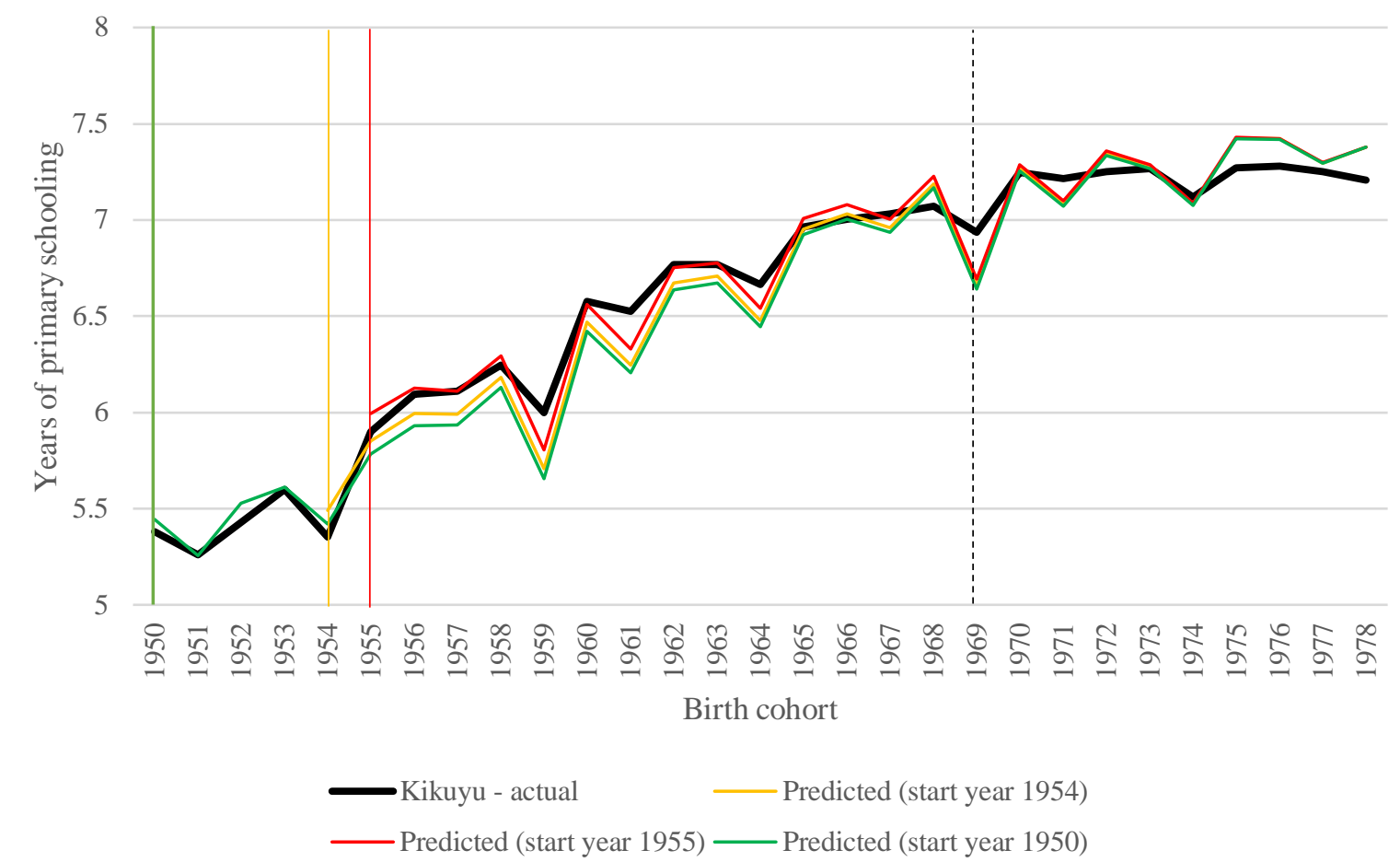

Source: pooled data from Kenyan 1969-2009 censuses, Minnesota Population Center, 2018. 
Figures 3a and 3b. Average years of secondary schooling among all respondents with at least 7 years of primary schooling
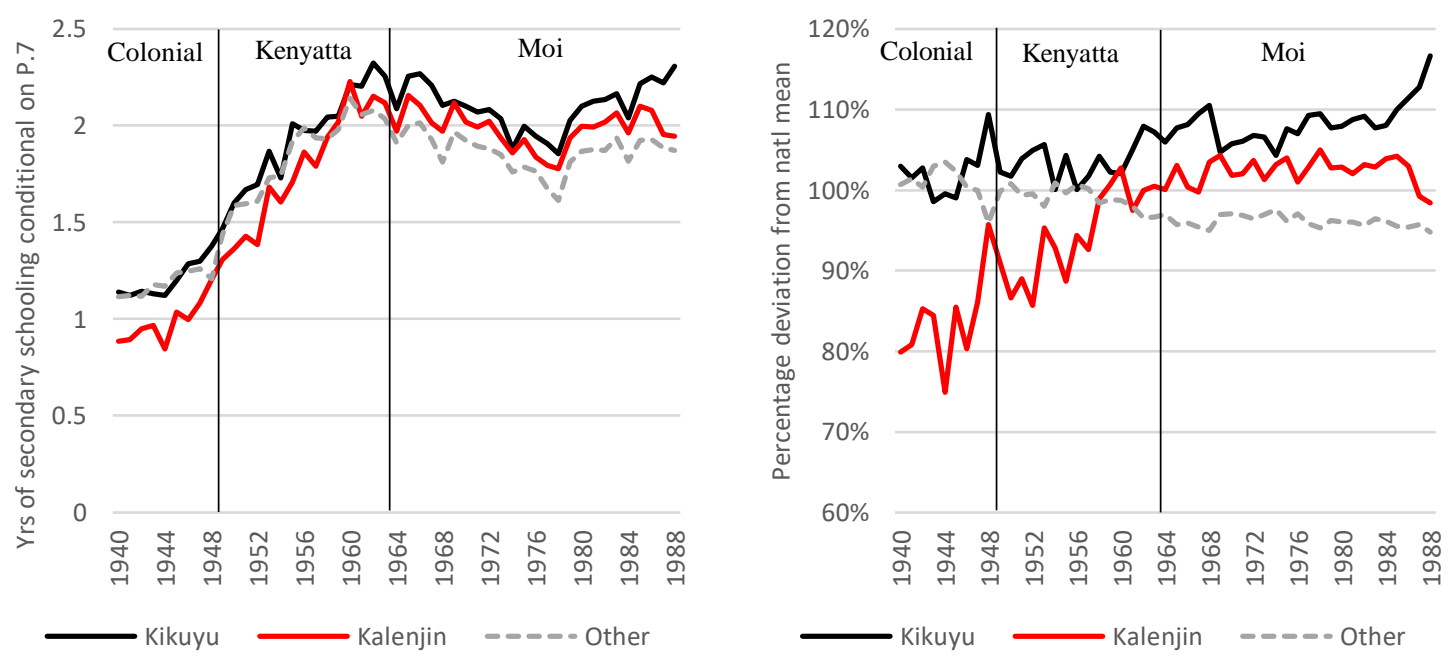

Note: Nairobi-born respondents excluded (constitute $<2 \%$ ); droplines mark cohorts who are expected to have received most of their schooling under the given 'regime'. Source: Pooled data from Kenyan 1969-2009 censuses, Minnesota Population Center, 2018. 
Table 1. Education expenditure by level of education and decade

\begin{tabular}{|l|r|r|r|r|r|}
\hline & 1971 & 1980 & 1992 & 2000 & 2011 \\
\hline \multicolumn{1}{|l|}{ Expenditure by level of education, as \% of government expenditure on education } \\
\hline Primary & 46 & 60 & 51 & 68 & 39 \\
\hline Secondary & 34 & 17 & 20 & 17 & 43 \\
\hline Tertiary & 15 & 18 & 20 & 12 & 13 \\
\hline Per student expenditure as multiple of expenditure per primary student & 1 & \\
\hline Primary & 1 & 1 & 1 & 2 & 6 \\
\hline Secondary & 8 & 3 & 3 & 15 & 16 \\
\hline Tertiary & 36 & 46 & 31 & & 1 \\
\hline
\end{tabular}

Source: Expenditure: World Development Indicators, 2019; Student enrolment: Simson, 2019. 
Table 2. Regression results: ethnic match effect on years of primary schooling, using quadratic group-specific time trends, pooled DHS data

\begin{tabular}{lcccccc}
\hline & $(1)$ & $(2)$ & $(3)$ & $(4)$ & $(5)$ & $(6)$ \\
Primary & $\begin{array}{c}\text { Primary } \\
\text { Years }\end{array}$ & $\begin{array}{c}\text { Primary } \\
\text { Years }\end{array}$ & $\begin{array}{c}\text { Primary } \\
\text { Years }\end{array}$ & $\begin{array}{c}\text { Primary } \\
\text { Years }\end{array}$ & $\begin{array}{c}\text { Primary } \\
\text { Years }\end{array}$ \\
\hline & & & & & & \\
Ethnic match & $0.185^{* * *}$ & 0.0642 & -0.0641 & -0.0549 & -0.0478 & $0.0986^{*}$ \\
& $(0.0431)$ & $(0.0545)$ & $(0.0551)$ & $(0.0524)$ & $(0.0541)$ & $(0.0572)$ \\
Controls & & & & & & YES \\
Religion & YES & YES & YES & NO & YES & NO \\
Place of birth (urban/rur) & YES & YES & NO & NO & NO & YES \\
Gender & YES & YES & YES & NO & YES & 72,943 \\
Observations & 47,146 & 46,729 & 90,645 & 90,645 & 70,647 & 0.270 \\
R-squared & 0.249 & 0.245 & 0.241 & 0.158 & 0.262 & 0.26 \\
\hline
\end{tabular}

Robust standard errors in parentheses

$* * * \mathrm{p}<0.01, * * \mathrm{p}<0.05, * \mathrm{p}<0.1$

Notes:

Model 1: 'Narrow' replication of KP model in Appendix B, Column 2, Row 1

Model 2: As M1 but replaces birth year variable with actual recorded birth year

Model 3: As M2 but adds data from 2014 DHS

Model 4: As M3 but excluding all controls

Model 5: As M3 but restricts age of sampled respondents to $>=20$

Model 6: As M4 but extends birth cohorts included to those born in 1950 or later 
Table 3. Regression results: ethnic match effect on years of primary schooling, using quadratic group-specific time trends, pooled census data

\begin{tabular}{|c|c|c|c|c|c|c|}
\hline VARIABLES & $\begin{array}{c}(1) \\
\text { Primary } \\
\text { Years }\end{array}$ & $\begin{array}{c}(2) \\
\text { Primary } \\
\text { Years }\end{array}$ & $\begin{array}{c}(3) \\
\text { Primary } \\
\text { Years }\end{array}$ & $\begin{array}{c}(4) \\
\text { Primary } \\
\text { Years }\end{array}$ & $\begin{array}{c}(5) \\
\text { Primary } \\
\text { Years }\end{array}$ & $\begin{array}{c}(6) \\
\text { Primary } \\
\text { Years }\end{array}$ \\
\hline District ethnic match & $\begin{array}{l}0.139 * * \\
(0.0553)\end{array}$ & $\begin{array}{c}0.113^{*} \\
(0.0545)\end{array}$ & $\begin{array}{c}0.0424 \\
(0.0560)\end{array}$ & $\begin{array}{l}0.150 * * \\
(0.0393)\end{array}$ & & \\
\hline $\begin{array}{l}\text { District ethnic match } \\
\text { placebos }\end{array}$ & & & & & $\begin{array}{c}0.167 * * * \\
(0.0365)\end{array}$ & $\begin{array}{l}0.124 * * \\
(0.0545)\end{array}$ \\
\hline Controls & & & & & & \\
\hline Religion & NO & NO & NO & $\mathrm{NO}$ & NO & NO \\
\hline Place of birth (urban/rur) & NO & NO & NO & NO & NO & NO \\
\hline Gender & NO & NO & NO & NO & $\mathrm{NO}$ & NO \\
\hline Weights & YES & YES & YES & YES & YES & YES \\
\hline Observations & $3,114,944$ & $2,293,126$ & $2,228,676$ & $2,455,153$ & $2,455,153$ & $2,455,153$ \\
\hline R-squared & 0.137 & 0.148 & 0.139 & 0.167 & 0.162 & 0.162 \\
\hline
\end{tabular}

Robust standard errors in parentheses

$* * * \mathrm{p}<0.01, * * \mathrm{p}<0.05, * \mathrm{p}<0.1$

Notes:

Model 1: 'Close' replication of KP model in Appendix B, Column 2, Row 1 (birth cohorts 1954-95)

Model 2: As M1 but restricts age of sampled respondents to $>=20$

Model 3: As M2 but narrows birth cohort inclusion to those born in 1955 or after

Model 4: As M2 but extends birth cohort inclusion to those born in 1950 or after

Model 5: As M4 but using a placebo match dummy where the K-M transition is moved forward 3 years

Model 5: As M4 but using a placebo match dummy where the K-M transition is moved backward 3 years 
Table 4. Regression results: effect of average district KCPE score on the share of secondary students to primary completers

\begin{tabular}{lc|c|c}
\hline & \multicolumn{3}{c}{$\begin{array}{c}\text { District rate of primary-secondary } \\
\text { transition }(1989)\end{array}$} \\
\hline Average KCPE score & $0.00199 * *$ & $0.00209 * *$ & $0.00174 *$ \\
& $(0.000787)$ & $(0.000781)$ & $(0.000885)$ \\
Kalenjin dummy & & 0.0727 & \\
& & $(0.0527)$ & \\
Kikuyu dummy & & & 0.0362 \\
& & & $(0.0562)$ \\
Constant & -0.289 & -0.312 & -0.208 \\
& $(0.270)$ & $(0.267)$ & $(0.299)$ \\
Observations & & & \\
R-squared & 40 & 40 & 40 \\
\hline
\end{tabular}

Source: Data assembled from Kenafric Industrial Services, 1991, Kenya's Primary and Secondary Schools Network: A Statistical Presentation, sponsored by Christian Churches.

Notes: Lamu excluded from the sample due to missing data. Rate of transition calculated by dividing $1 / 4$ of total secondary enrolment in 1989 the number of 1989 KCPE candidates. All models are estimated using OLS. $* * * \mathrm{p}<0.01, * * \mathrm{p}<0.05, * \mathrm{p}<0.1 ;$ standard errors in parentheses. 
Table 5. Primary school teacher supply by province

\begin{tabular}{|c|c|c|c|c|c|c|c|c|c|c|c|c|c|c|c|}
\hline \multirow[b]{2}{*}{ Province } & \multicolumn{4}{|c|}{$\begin{array}{l}\text { Teachers by } \\
\text { province }\end{array}$} & \multicolumn{4}{|c|}{ School-aged population (6-13) } & \multicolumn{4}{|c|}{$\begin{array}{l}\text { population to } \\
\text { teacher ratio }\end{array}$} & \multicolumn{3}{|c|}{ Pop to teacher ratio, \% change } \\
\hline & 1966 & 1977 & 2003* & 2014* & 1966 & 1977 & 2003 & 2014 & 1966 & 1977 & 2003 & 2014 & $\begin{array}{c}\text { 'Kenyatta } \\
\text { era' } \\
(1966-77)\end{array}$ & $\begin{array}{c}\text { 'Moi era' } \\
(\mathbf{1 9 7 7 - 2 0 0 3 )}\end{array}$ & $\begin{array}{c}\text { Kibaki } \\
\text { era' } \\
(2003-14) \\
\end{array}$ \\
\hline Central & 8,183 & 16,571 & 24,689 & 22,041 & 346,987 & 569,251 & 803,358 & 921,576 & 42 & 34 & 33 & 42 & $-19 \%$ & $-5 \%$ & $28 \%$ \\
\hline Coast & 1,969 & 5,758 & 11,217 & 14,482 & 173,813 & 265,542 & 584,314 & 767,204 & 88 & 46 & 52 & 53 & $-48 \%$ & $13 \%$ & $2 \%$ \\
\hline Eastern & 6,384 & 18,001 & 37,839 & 40,584 & 403,449 & 622,737 & $1,149,693$ & $1,372,019$ & 63 & 35 & 30 & 34 & $-45 \%$ & $-12 \%$ & $11 \%$ \\
\hline Nairobi & 1,609 & 2,935 & 4,390 & 4,278 & 70,018 & 66,880 & 341,424 & 488,556 & 44 & 23 & 78 & 114 & $-48 \%$ & $241 \%$ & $47 \%$ \\
\hline North-East & 69 & 330 & 1,094 & 2,882 & 55,237 & 81,864 & 361,274 & 779,028 & 801 & 248 & 330 & 270 & $-69 \%$ & $33 \%$ & $-18 \%$ \\
\hline Nyanza & 6,014 & 16,458 & 29,936 & 35,646 & 468,032 & 618,661 & $1,115,305$ & $1,374,139$ & 78 & 38 & 37 & 39 & $-52 \%$ & $-1 \%$ & $3 \%$ \\
\hline Rift & 5,176 & 16,681 & 46,960 & 54,553 & 460,244 & 719,435 & $1,886,964$ & $2,572,519$ & 89 & 43 & 40 & 47 & $-51 \%$ & $-7 \%$ & $17 \%$ \\
\hline Western & 4,118 & 13,039 & 21,443 & 27,156 & 300,511 & 432,318 & 902,130 & $1,136,232$ & 73 & 33 & 42 & 42 & $-55 \%$ & $27 \%$ & $-1 \%$ \\
\hline $\begin{array}{l}\text { Total } \\
\text { Coefficient } \\
\text { of } \\
\text { Variation }\end{array}$ & 33,522 & $\mathbf{8 9 , 7 7 3}$ & 177,568 & 201,622 & $2,278,290$ & $3,380,717$ & $7,144,462$ & $9,411,273$ & 68 & 38 & 40 & 47 & $-45 \%$ & $7 \%$ & $16 \%$ \\
\hline
\end{tabular}

*Teachers in public schools only.

Sources: MoE Triennial Survey, 1964-66 and annual report for 1966; MoE annual report 1977; Data from 2003 from Republic of Kenya, Ministry of Education \& UNESCO, (2012) Kenya education for all evaluation, end decade assessment 2000-10, Table 3.4; MoEST, Kenya 2014 basic education statistical booklet. Population data projected from censuses 1969, 1979, 1999 and 2009. 


\section{Appendix 1. DHS versus census data compared}

The Demographic and Health Survey (DHS) and census data each have different strengths and weaknesses. The main advantage of the DHS is that it measures self-reported ethnic identity, while its disadvantage is a skewed gender and age sample (as the DHS is based on interviews with women of reproductive age and a subset of their husbands). Relative to the census, the sample size is also considerably smaller $(\mathrm{n}=\sim 70,000$, compared to $\mathrm{n}=\sim 2,500,000)$.

The census, in contrast to the DHS, does not make self-reported ethnicity data available. The census results therefore rest on an ethnicity proxy. Respondents are classified as belonging to the ethnic group that dominates their county of birth. As many counties are relatively ethnically homogenous, this is a credible assumption, although it does introduce room for error. In particular, it does mean that people born in the main urban metropolises, Nairobi and Mombasa, cannot be classified, and are included in a residual 'mixed ethnicity region' category instead. (Note however that the share of people born in these urban areas is still comparatively small, at roughly $2 \%$ in Nairobi and $1 \%$ in Mombasa, in our full pooled sample).

In the figures below we compare the two samples to see how closely they align. We plot the average years of primary schooling using the ethnic group categories applied in the paper (Kikuyu, Kalenjin and other). Female and male samples are treated separately (due to the gender skew in the DHS sample).

The trends across the two data samples are similar, although the DHS systematically estimates higher average years of schooling. Unsurprisingly, the volatility in trend is higher for the oldest cohorts, and particularly so for the smaller DHS sample and more so for the male than female sample (as the DHS male sample is smaller). However, there are no systematic differences between the two samples that seem to align with Kenya's presidential transitions (cohorts born after 1954 or 1967).

Note that both samples show signs of age heaping - we see troughs on round ages ( $5 \mathrm{~s}$ and $10 \mathrm{~s}$ ), as age heaping is more common among the less educated. Because the census is undertaken at regular 10 year intervals, the census age heaping effects are more regular than for the unevenly spaced DHSs.

Our main figures utilise the census instead of DHS data, given the larger sample size (and thus less year-to-year fluctuations), and gender balance. 
Appendix Figure 1. Years of primary schooling by birth year, census and DHS data compared Female Sample

Kikuyu

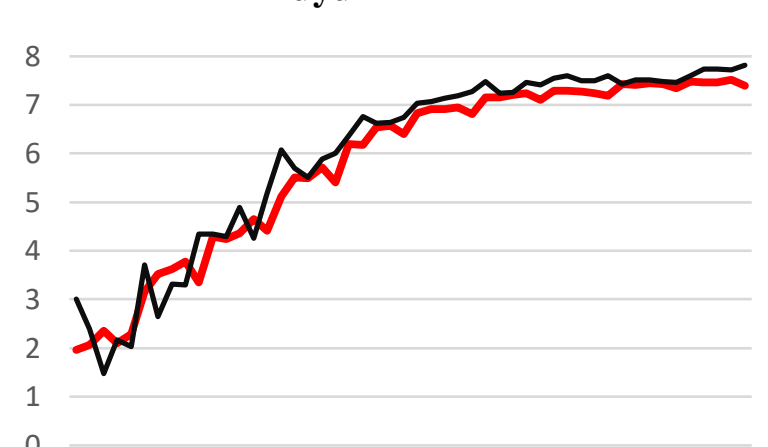

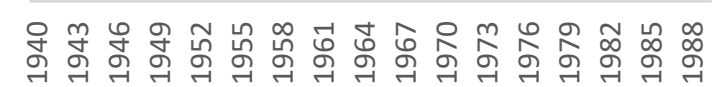

census

Kikuyu

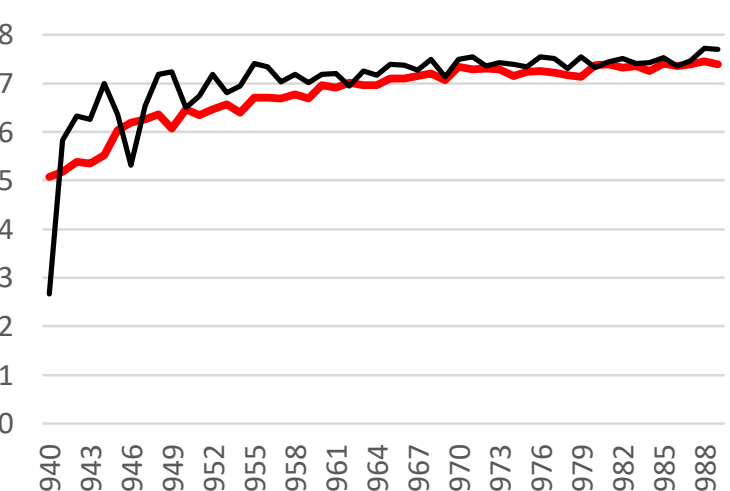

Kalenjin

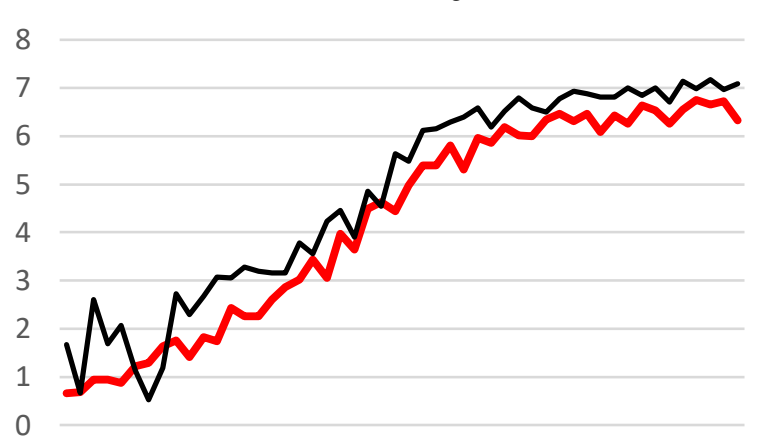

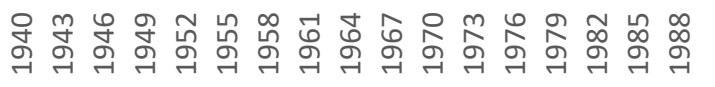

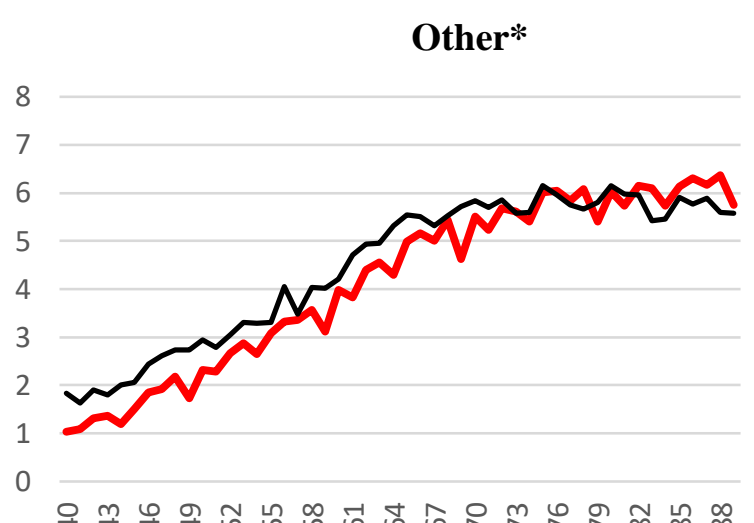

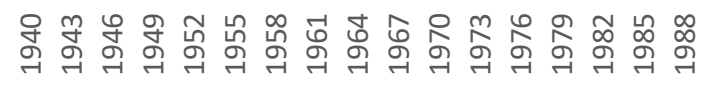

Male Sample

Kalenjin

8

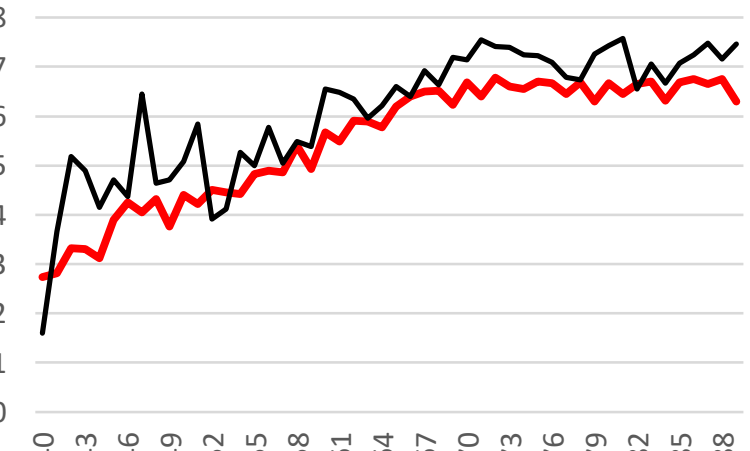

Other*

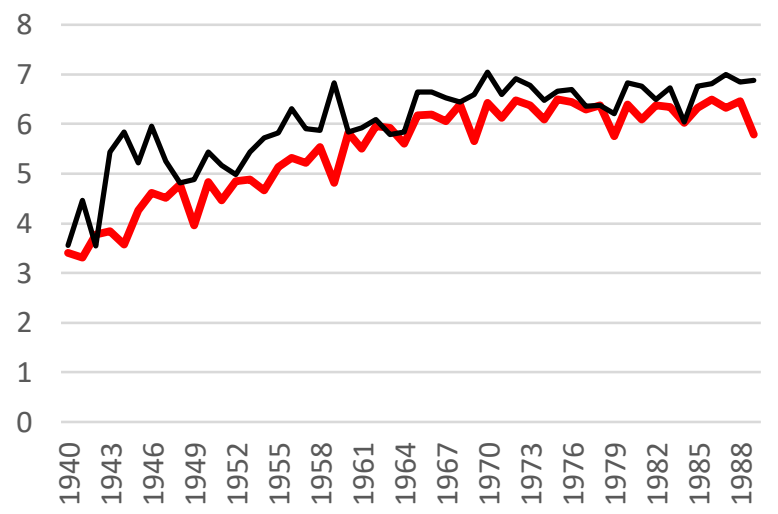

* Nairobi-born respondents excluded.

44 


\section{Appendix Figure 2. Kenya: secondary attainment by ethnic group}

a. Average years of secondary schooling by group

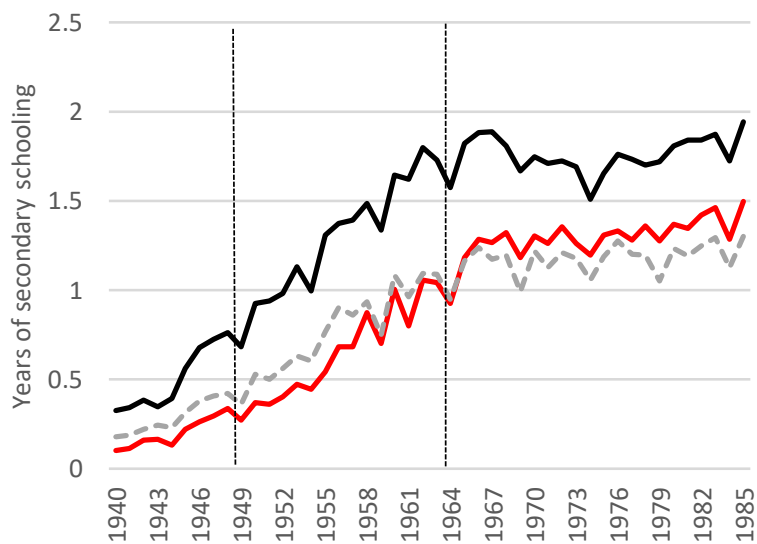

b. Secondary schooling by group relative to mean

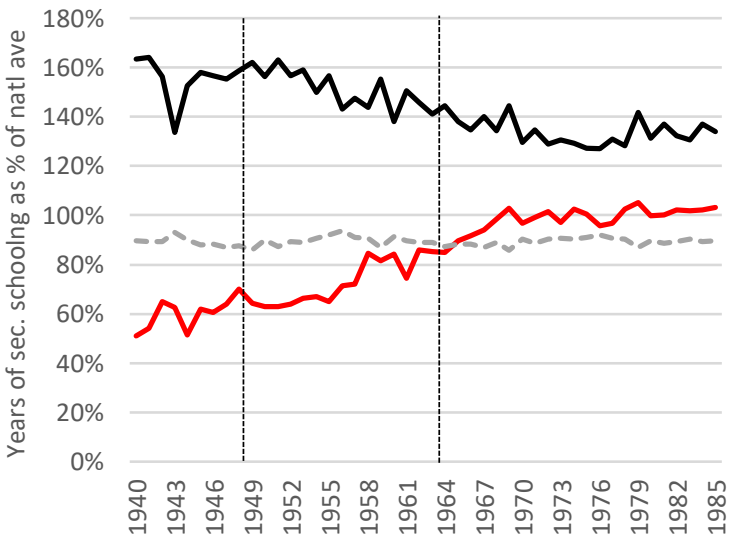

c. Secondary schooling by group, difference to mean

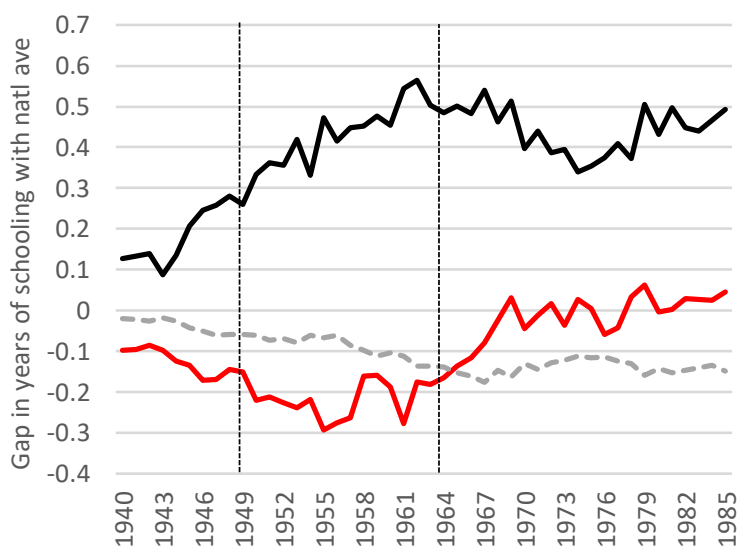

- Kikuyu Kalenjin $\ldots-\infty$ Other

Notes: Include respondents >=24; Nairobi-born respondents excluded; vertical lines mark those cohorts most likely educated in the colonial era, under President Kenyatta and under President Moi, respectively.

Source: Pooled data from Kenyan 1969-2009 censuses, Minnesota Population Center, 2018. 


\section{Appendix 3. Age of school attendance}

The papers measuring ethnic favouritism in primary education rest on assumptions about the age at which children begin and finish their schooling. The respondents predicted age of schooling determines under which president the respondent was educated under. In this paper we have followed Kramon and Posner (2016) and $\mathrm{Li}$ (2018) in assuming that children start primary school at age 6 and complete it at age 13, but it is important to recognize that this is not an unproblematic assumption.

The Kenyan census data shows that most students do not in fact start and complete at these prescribed ages. Appendix Table 1 gives the age distribution of (2009) census respondents who list their highest level of education to be Standard 7, but report still being in school. We can assume that most of these respondents are currently in Standard 8 (the last year of primary school). Only $17 \%$ of these students in their last year of primary school are aged 13 years or less and a full $21 \%$ are 18 years or above.

This lack of age-school attendance precision matters for two reasons. First, it means that the dummy identifying students educated under a co-ethnic president is not precise, which means that the data is unlikely to pick up any sharp discontinuity around the time of a presidential transition. Second, it risks biasing the observed ethnic composition of the younger cohorts if the age at which a student completes primary schooling is correlated with ethnicity.

The census data suggests that such biases are indeed large. The ages at which Kenyan students complete primary school varies considerably by region. Students born in the richest part of the country, such as Nairobi and the Central Province, complete their primary schooling at a younger age, on average, than those from more peripheral regions of the country. The average age of students in their final year of primary school in $2009^{16}$ is 14 years among respondents born in Nairobi, 15.1 among those born in the Central Province, and 16.3 years in the remainder of the country. The model will therefore pick up a higher relative educational performance for respondents from richer communities than would be the case if those same respondents were interviewed five years later in time. Given that the Kikuyu reside in some of Kenya's wealthiest regions, this will bias their performance upward. In Kramon and Posner's (2016) model this upward bias in Kikuyu educational attainment coincides, roughly, with the Kibaki presidency, and may therefore be mistaken for ethnic favouritism. For this reason, we include alternative specifications that use a higher cut-off age (>=20), by which age $\sim 95 \%$ of students will have completed their primary schooling. Unfortunately, this means that the datasets capture little of the educational dynamics after the election of President Kibaki.

Appendix Table 1. Distribution of Kenyan students who have completed P.7 and still report being in school, by age

\begin{tabular}{|r|r|r|r|}
\hline \multicolumn{1}{l|}{ Age } & \multicolumn{1}{l|}{ P } & Percentage & Cumulative \\
\hline$<=13$ & 13,296 & $17 \%$ & $17 \%$ \\
\hline 14 & 14,939 & $19 \%$ & $35 \%$ \\
\hline 15 & 14,166 & $18 \%$ & $53 \%$ \\
\hline 16 & 11,855 & $15 \%$ & $68 \%$ \\
\hline 17 & 8,777 & $11 \%$ & $79 \%$ \\
\hline 18 & 6,266 & $8 \%$ & $87 \%$ \\
\hline 19 & 3,543 & $4 \%$ & $91 \%$ \\
\hline 20 & 2,346 & $3 \%$ & $94 \%$ \\
\hline 21 & 1,028 & $1 \%$ & $95 \%$ \\
\hline$>=22$ & 3652 & $5 \%$ & $100 \%$ \\
\hline
\end{tabular}

\footnotetext{
${ }^{16}$ I.e., those who have completed standard 7 but report still being in school.
} 


\section{Appendix 4. Confusing controls?}

A further debatable choice on the part of Kramon and Posner (2016) and $\mathrm{Li}$ (2018) is the inclusion of controls for the individual respondent's gender, religion and birth in an urban versus rural area, in their models of ethnic favouritism. By introducing dummies (without interactions), the authors assume that the impact of gender, religion or urban-rural birth location on attainment remains static over time and unrelated to level of a group's educational attainment. This is clearly not the case, given the strong gender convergence in primary attendance and high rates of urbanisation. Furthermore, given that the gender composition of each ethnic group is unlikely to be changing over time, it is unclear why this variable is relevant in the first place. Instead, it could confound the group trends by predicting a lower/higher attainment level for females at the beginning/end of the period, owing to the application of a dummy that calculates the average gender gap across the period, despite its sharp decline in the gender disparity in primary schooling over time. A more appropriate way of dealing with the gender imbalance in the DHS sample would be to use split samples.

Religion, similarly, should only influence our variable of interest if the religious compositions of ethnic groups are changing. If this is indeed the case, it seems very possible that the relationship between religion and education will be changing with it, as religions tend to evolve with the composition of their adherents.

Lastly, if the urban-rural composition of ethnic groups are changing at different rates while the attainment gap between urban and rural areas are decreasing, it may skew the estimated attainment level for groups that urbanise faster towards the end or beginning of the period. For this reason we present data and re-run models that both include and exclude these controls. 
Appendix Table 5. Regression results: ethnic match effect on years of secondary schooling, sample restricted to primary school completers

\begin{tabular}{|c|c|c|c|c|}
\hline VARIABLES & $\begin{array}{c}(1) \\
\text { Secondary } \\
\text { Years } \\
(\mathrm{DHS}) \\
\end{array}$ & $\begin{array}{c}(2) \\
\text { Secondary } \\
\text { Years } \\
(\mathrm{DHS}) \\
\end{array}$ & $\begin{array}{c}(3) \\
\text { Secondary } \\
\text { Years } \\
(\mathrm{DHS}) \\
\end{array}$ & $\begin{array}{c}(4) \\
\text { Secondary } \\
\text { Years } \\
\text { (Census) }\end{array}$ \\
\hline Ethnic match & $\begin{array}{l}0.1311^{*} \\
(0.0625)\end{array}$ & $\begin{array}{l}0.1323 * \\
(0.0652)\end{array}$ & $\begin{array}{c}0.0861 \\
(0.0768)\end{array}$ & \\
\hline District ethnic match & & & & $\begin{array}{c}-0.026 \\
(0.0399)\end{array}$ \\
\hline \multicolumn{5}{|l|}{ Controls } \\
\hline Religion & YES & NO & NO & NO \\
\hline Place of birth (urban/rural) & YES & NO & NO & NO \\
\hline Gender & YES & $\mathrm{NO}$ & $\mathrm{NO}$ & YES \\
\hline Weights & NO & NO & NO & YES \\
\hline Observations & 39,258 & 39,258 & 34,582 & $1,388,516$ \\
\hline R-squared & 0.0241 & 0.0159 & 0.0124 & 0.0166 \\
\hline
\end{tabular}

Robust standard errors in parentheses

$* * * \mathrm{p}<0.01, * * \mathrm{p}<0.05, * \mathrm{p}<0.1$

Notes:

Model 1: Based on KP model in Table 3, column 1, incl. DHS 2014 (birth cohorts 1950-93, aged 21 and above) Model 2: Like Model 1, but excluding controls.

Model 3: Like Model 2, but limiting birth cohorts to 1950-1988.

Model 4: Based on KP model in Table 3, column 7 (birth cohorts 1950-88, aged 21 and above) 
Appendix Table 6: Average KCPE Score by Ethnic Region

\begin{tabular}{|l|c|r|}
\hline 'Ethnic region' & $\begin{array}{l}\text { Average } \\
\text { KCPE score }\end{array}$ & $\begin{array}{l}\text { Ave years of } \\
\text { primary schooling }\end{array}$ \\
\hline Nairobi & 368 & 7.5 \\
\hline Turkana & 367 & 1.1 \\
\hline Embu & 366 & 6.9 \\
\hline Kikuyu & 363 & 7.3 \\
\hline Kalenjin & 350 & 6.4 \\
\hline Luhya & 345 & 6.6 \\
\hline Luo & 345 & 6.9 \\
\hline Kamba & 337 & 6.9 \\
\hline Kisii & 333 & 7 \\
\hline Somali & 328 & 6.9 \\
\hline Mombasa & 327 & 6.3 \\
\hline Meru & 324 & 4.8 \\
\hline Mijikenda & 304 & 6.3 \\
\hline & & \\
\hline National average & 345 & \\
\hline Coefficient of Variation $($ CoV) & 0.058 & \\
\hline CoV between schools within districts (ave) & 0.130 & \\
\hline St. dev. across all schools & 49 & \\
\hline Source: Data assembl & & \\
\hline
\end{tabular}

Source: Data assembled from Kenafric Industrial Services, 1991, Kenya’s Primary and Secondary Schools Network: A Statistical Presentation, sponsored by Christian Churches.

Notes: 'Ethnic region' is defined here as those districts where the given ethnic group constitutes at least $50 \%$ of population (based on the 2009 census). Districts with less than $50 \%$ of their population from any one ethnic group are excluded. 
Appendix Figure 7. Convergence in years of primary education: ethnic group average years of schooling as $\%$ of national average

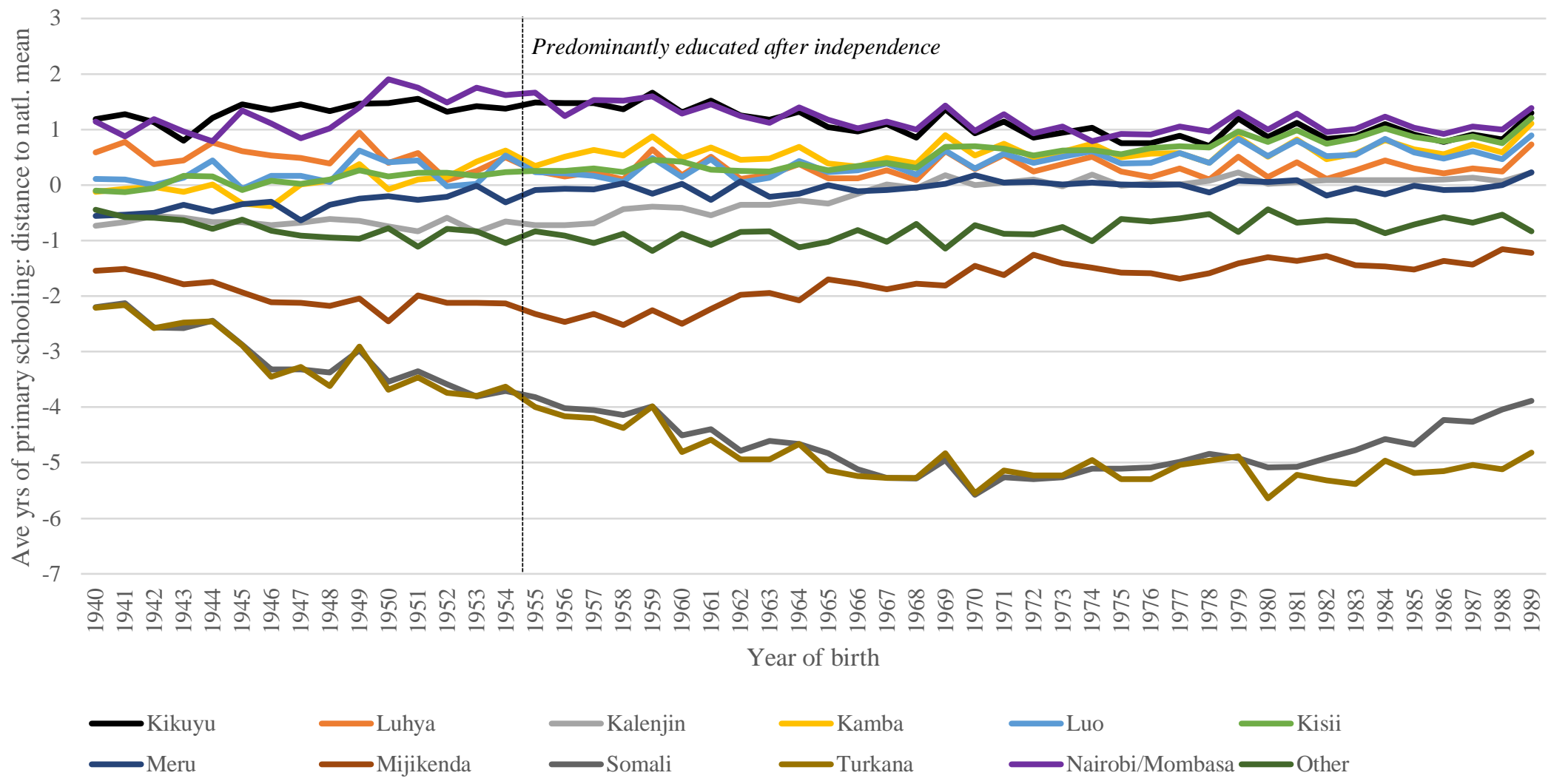

Source: pooled data from Kenyan 1969-2009 censuses, Minnesota Population Center, 2018. 